\title{
OBSERVATIONS OF INTERACTIONS BETWEEN INTERPLANETARY AND GEOMAGNETIC FIELDS
}

\section{J. L. BURCH}

GSFC GODDARD SPACE FLIGHT CENTER GREENBELT, MARYLAND

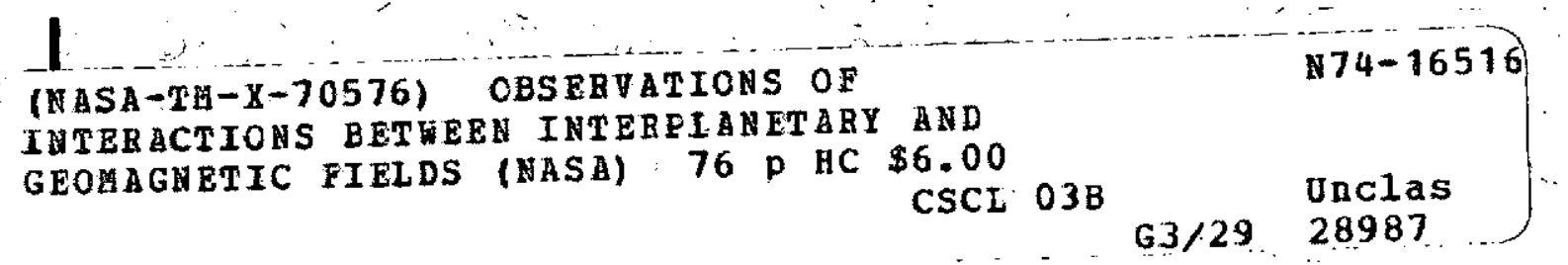




\title{
OBSERVATIONS OF INTERACTIONS BETWEEN \\ INTERPLANETARY AND GEOMAGNETIC FIELDS
}

\author{
By \\ J. L. Burch \\ NASA-Goddard Space Flight Center \\ Greenbe1t, Maryland 20771
}

DECEMBER 1973

Submitted to Reviews of Geophysics and Space Physics 
TABLE OF CONTENTS

Page

Introduction $\ldots \ldots \ldots \ldots \ldots \ldots \ldots \ldots \ldots \ldots \ldots \ldots \ldots \ldots$

The Interplanetary Magnetic Field and

Magnetospheric Convection ..................... 3

Disturbances Affecting $\mathrm{AE}$ and $\mathrm{Kp} \ldots \ldots \ldots \ldots \ldots \ldots \ldots \ldots \ldots \ldots \ldots \ldots \ldots$

Tail-Lobe Magnetic Variations $\ldots \ldots \ldots \ldots \ldots \ldots \ldots \ldots \ldots \ldots \ldots \ldots$

Plasma and Magnetic Behavior Near the Neutral Sheet ........ 17

Dayside Flux Erosion and Expansion of the Polar Cap ........ 21

The Interplanetary Magnetic Field and Ring-

Current Development ......................... 39

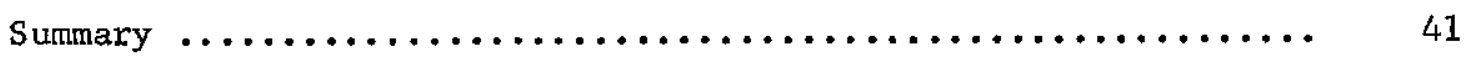




\section{ABSTRACT}

Magnetospheric effects associated with variations of the north-south component of the interplanetary magnetic field are examined in light of recent experimental and theoretical results. Although the occurrence of magnetospheric substorms is statistically related to periods of southward interplanetary magnetic field, the details of the interaction are not understood. In particular, attempts to separate effects resulting directly from the interaction between the interplanetary and geomagnetic fields from those associated with substorms have produced conflicting results. One can, however, say with some assurance that the transfer of magnetic flux from the dayside to the nightside magnetosphere, as evidenced by equatorward motion of the polar cusp and increases of the magnetic energy density in the lobes of the geomagnetic tail, is a direct consequence of the southward interplanetary magnetic field. On the other hand, the formation of a macroscopic $\mathrm{X}$-type neutral line at tail distances less than $35 \mathrm{R}_{\mathrm{E}}$ appears to be a substorm phenomenon. Although other plasma and field phenomena in the outer magnetosphere and at low altitudes may be directly associated with the southward interplanetary magnetic fie1d, the evidence is less convincing. The quantitative results which have been obtained are compared to current theoretical models of the reconnection process. 


\section{1}

INTRODUCTION

At the earth's orbit the average kinetic energy flux of the solar wind is approximately $5 \times 10^{-12}$ watts $\mathrm{m}^{-2}$, which is more than adequate to drive continuously any known magnetosphe ric disturbance. However, while this energy flux is continuously effective in confining and distorting the earth's magnetic field, it does not continuously drive any but the weakest of magnetospheric disturbances. The sporadic nature of geomagnetic activity has been found to be controlled by the magnetic and electric fields of the solar wind. Specifically, the transfer of solarwind energy into the magnetosphere is most efficient when the interplanetary magnetic field (IMF) has a southward component. The immediate effects of transitions to a more southward IMF are understandable in terms of large-scale reconfigurations of the magnetosphere involving a net transfer of magnetic flux from the dayside to the nightside. This flux transfer results in a shrinkage of the dayside magnetosphere and an increase of the magnetic energy density in the geomagnetic tail. Substorms that occur when the magnetosphere is reconfigured in this way generally penetrate deeper, that is, to lower latitudes, and involve the dissipation of much greater amounts of energy than substorms which occur following periods with only weak or non-existent southward IMF components. The purpose of this review is to summarize our present state of knowledge regarding the role of the solar-wind, or interplanetary, magnetic and electric fields in producing these large-scale magnetospheric reconfigurations. Particular attention is directed toward distinguishing the direct effects of the interactions between the interplanetary and geomagnetic fields from the indirect effects which are actually part of the 
substorm process. Its restricted scope necessarily results in rather light treatments of the important effects associated with the weakly disturbed or average magnetospheric configuration as deduced from observations of the entry of solar cosmic rays into the magnetosphere and the asymmetries in polar-cap convection patterns resulting from variations in the azimuthal component of the interplanetary magnetic field. For recent reviews of these topics see Morfill and Scholer (1973) on solar particle effects and Wilcox (1972) on IMF azimuthal effects. 
THE INLERPLANETARY MAGNETIC FIELD AND MAGNETOSPHERIC CONVECTION

The possibility of large-scale convection of magnetospheric plasma was initially considered by Gold (1959), Dungey (1961) and Axford and Hines (1961). Above about $300 \mathrm{~km}$ altitude (Walbridge, 1967) the magnetospheric plasma is, like the solar-wind plasma, collisionless and thus highly conducting. Therefore, bulk flow or convection of magnetospheric plasma can be driven by any static electric fields which are impressed on the magnetosphere. Conversely, bulk flow produced by pressure gradients (Gold, 1959) or viscous interactions (Axford and Hines, 1961) wil1 result in the production of polarization electric fields so that, in any case, the frozen-in-flux condition $(\bar{E}=-\bar{v} \times \bar{B})$ is satisfied in the coldplasma limit. For discussions of the frozen-in-flux concept of magnetohydrodynamics see Alfven and Fälthammar (1963) and Cowling (1956). The plasma flow inside the magnetosphere is not as simple as the flow of the solar wind that drives it since, due to strong magnetic field gradients, particle acceleration occurs. These same gradients act to impede the flow (Atkinson; 1966, 1972). Restriction of the convective plasma circulation also results from dissipation in the ionosphere be 1 ow $300 \mathrm{~km}$, where collisions do occur, allowing the flow of Pedersen currents parallel to the electric field. These effects plus wave-particle interactions, field-aligned electric fields and particle-shielding phenomena all combine to make convection a complicated process of magnetosphere-ionosphere coupling. Comprehensive reviews of the topic have been written by Axford (1969), Vasyliunas (1972), Wolf (1973) and Chappel1 (1973). 
That the patterns of quiet-time convection are determined 1 argely by the orientation of the interplanetary magnetic field has recently been confirmed in analyses of polar-cap magnetic variations by Svaalgard (1968), Mansurov (1969), and Friis-Christensen et a1 (1972). These variations have been interpreted by Svaalgard (1973) as consistent with an ionospheric Hall current at approximately $80^{\circ}$ magnetic latitude which circulates eastward and westward in the northern polar cap for IMF solarmagnetospheric $Y$ components (Ness, 1965) which are positive and negative respectively. The opposite behavior is noted in the southern polar cap. These characteristic variations are present on all days, although Kawasaki et al (1973) have noted that the IMF azimuthal effect is more obvious during magnetically disturbed periods.

Further evidence for the IMF control of the patterns of convection has been obtained by Heppner (1972) who has observed a consistent dawndusk asymmetry in polar-cap electric fields which is controlled by the IMF azimuthal component irrespective of the overall degree of activity. Three-dimensional mode1s of the open magnetosphere involving the superposition of a constant magnetic field and a dipole field have been examined by Stern (1973) and Gonzalez (1973), who used it to map the interplanetary electric field into the polar caps in a manner qualitatively consistent with the observations of Svaalgard (1973) and Heppner (1972).

Although viscous interactions or other means of producing tangentia1 stresses on the magnetopause have not definitively been ruled out, the above observations have established that the interaction between the interplanetary and geomagnetic fields is an important driving mechanism for 
magnetospheric convection, and that a reconnection model such as the one described by Dungey (1961) for purely southward IMF's may be applicable for all relative orientations of the two magnetic fields. Further support for a configuration in which polar-cap field lines are always connected to interplanetary field lines has been provided by the observations of direct magnetotail entry of solar-cosmic-ray protons (Morfill and Scholer, 1972) and electrons (Lin and Anderson, 1966). 
DISTURBANCES AFFECTING AE AND KP

The first observational evidence that interactions with the interplanetary magnetic field were, as suggested by Dungey (1961), responsible for magnetospheric activity was presented by Fairfield and Cahill (1966) who noted that high-latitude magnetic disturbances were associated with southward-directed magnetosheath magnetic fields. This relationship has been confirmed by many subsequent investigations. Notably Wilcox et a1 (1967), Hirshberg and Colburn (1969), Arnoldy (1971) and Foster et a1 (1971) have demonstrated that among a11 measured solar-wind plasma and field parameters the southward component of the interplanetary magnetic field correlates best with the statistical occurrence of ground magnetic disturbances registered by the $\mathrm{Kp}$ or $\mathrm{AE}$ indices (Rostoker, 1972). The work of Garrett (1973) has shown further that the average $\mathrm{AE}$ index during a "substorm interval" (defined by a single rise of $\mathrm{AE}$ into a range of values greater than $70 \mathrm{y}$ ) tends to be higher for a given integrated IMF southward component when the variance of the IMF is high. Following Arnoldy (1971), Garrett averaged the interplanetary magnetic parameters over periods equal in length to the substorm intervals but which began one hour earlier. This behavior, which persisted to a lesser degree after the expected solar-wind velocity dependence of the variance was included, is interpreted by Garrett to indicate the possibility that solarwind energy is transferred to the magnetosphere more efficiently when the variance is high, perhaps through an increase of the merging rate or through a hydromagnetic coupling mechanism such as the one suggested by Dessler and Fejer (1963). The possible importance of the variance when 
the IMF is northward has not however, been investigated specifically either in the work of Garrett or in the earlier investigations of the effects of the variance by Ballif et al (1969).

Another important result of the IMF statistical correlations with Kp and $A E$ activity has been that in two studies in which quantitative relationships were examined for more than one coordinate system, better correlation was found using solar-magnetospheric coordinates than either solar-equatorial (Hirshberg and Colburn, 1969) or solar-ecliptic (Arnoldy, 1971) coordinates. This result is consistent with expectations especially if, as suggested by Dungey (1961), the interaction with the interplanetary magnetic field takes place near the dayside equatorial plane. In this region magnetospheric field lines are expected to be nearly perpendicular to the earth-sun line and parallel to the plane formed by the earth-sun line and the earth's dipole axis, that is, the solar-magnetospheric X-Z plane (Ness, 1965). On the other hand, the orientations of the Z-axes of the solar-ecliptic and solar-equatorial systems are expected to maintain no consistent relationship with the magnetospheric field configuration. In fact, the observation by Arnoldy (1971) that the hourly average AE index exhibits a nearly linear statistical relationship with the solarmagnetospheric southward component while the interplanetary magnetic field is ordered in solar-equatorial coordinates (Coleman and Rosenberg, 1971) has been used by Russell and McPherron (1973) to explain the semiannual variation of geomagnetic activity. Their model predicts annual peaks for toward (spring peak) and away (fall peak) sectors which are consistent with observations covering the period 1962-1969 (Saito, 1972; 
Burch, 1973a). This result emphasizes further the importance of using an appropriate coordinate system in the study of these interactions. A1though other, less we11-investigated coordinate sytems (such as solarmagnetic) may eventually be shown to be even more appropriate, present evidence favors the solar-magnetospheric system and requires that this system be used in preference to solar-ecliptic or solar-equatorial if the various investigations are to be quantitatively compared. Convenient matrix formulations of the transformations between these coordinate systems have been described by Russe11 (1971).

Finally, information on the time-scale of the magnetospheric response to IMF fluctuations has been obtained in the cross-correlation studies of Arnoldy (1971), Kokubun (1972), Rostoker et a1 (1972), and Meng et a1 (1973), which have established that the growth and decay of the $\mathrm{AE}$ index follow variations in the interplanetary $B_{z}$ component with a time delay of about 40 minutes. An unambiguous interpretation of this time delay cannot, however, be reached from these studies since intervals of multiple substorms were included.

When assessing the implications of the various statistical correlations of interplanetary magnetic field parameters with auroral-zone magnetic activity the following points should be noted. First, the 40-minute 1ag between interplanetary and auroral-zone variations is an average effect. As pointed out by Levy et al (1964), Kawasaki et al (1971), and Rostoker et al (1972), the response time of the magnetosphere to interplanetary shock waves and directional discontinuities is on the order of one or two minutes. The magnetospheric response to such discontinuities at times 
includes rapid-onset negative bays in the auroral zone. Evidence has accumulated (Parks et al, 1972) that the probability of such external triggering of substorms is dependent on a favorable magnetospheric configuration or metastable state, and that (Burch, 1972a) the necessary magnetospheric conditions can be related to the average magnitude and direction of the interplanetary magnetic fleld for a period of time before the passage of the discontinuity. Specifically, the study of Burch (1972a) indicated that southward or nearly horizontal average interplanetary magnetic-field directions over the previous half-hour are required, with more northerly average directions associated with rather high (B $>10 \mathrm{\gamma}$ ) field magnitudes. A second point to note is that, while Arnoldy's (1971) results showed an approximately linear relationship between the hourlyaverage $\mathrm{AE}$ and the previous one-hour's integrated solar-magnetospheric southward component of the interplanetary magnetic field, $\mathrm{AE}$ activity does in fact occur in individual cases when the integrated southward component is zero. This point is evidenced in the results of Burch (1972a) noted above, Garrett (1973), and Tsurutani and Meng (1972) among others. Although the "rectifier effect" employed by Russe11 and McPherron (1973), in which the intensity of substorm activity is zero when no southward flux has reached the magnetosphere in the previous hour and is proportional to the integrated southward flux at other times, is justified by the results of Arnoldy (1971) for use in assessing mechanisms for the long-term statistical variations in geomagnetic activity, it is, of course, not applicable to individual substorms. Therefore, while we have established through statistical studies the importance of the interplanetary magnetic 
field in substorm magnetic variations in the auroral zone, correlated plasma and field observations in interplanetary space and at as many locations as possible in the magnetosphere during individual events offer the best hope of revealing the underlying physical processes involved. As noted above, the interplanetary magnetic field is now known to be an important driver of quiet-time or nearly steady-state convection, in which $\frac{\partial \bar{B}}{\partial t} \approx 0$ throughout the magnetosphere. However, disturbances that manifest themselves in $\mathrm{Kp}$ and $\mathrm{AE}$ involve unsteady convection and generally unstable conditions which (1) are difficult to relate to their external driving mechanisms, and (2) are associated with large-scale magnetospheric reconfigurations. In addition, recent studies (Akasofu et al, 1973; Weins and Rostoker, 1973) have demonstrated the inadequacy of the present sparse array of magnetic observatories in detecting the onset of many polar magnetic substorms that occur on isolated magnetic-1ocaltime meridians or at latitudes above the zone of maximum statistical occurrence of discrete auroras $\left(\Lambda \sim 63^{\circ}-70^{\circ}\right)$ where the $\mathrm{AE}$ stations are located. Since it is impossible with the existing instrumentation to determine the onset times, or even the existence, of all substorms, it is also impossible to determine unambiguously the necessary conditions for their occurrence. Accurate timing is, however, feasible for the onsets of some temporally - isolated la rge-scale substorms that are signalled by the rapid transition of the magnetic topology in a wide longitudinal sector of the nightside outer magnetosphere inside about $15 \mathrm{R}_{\mathrm{E}}$ from a distended tail-like configuration to a more dipolar configuration. The magnetospheric current system associated with this 
transition is detected by near-midnight equatorial. and midlatitude magnetometers as a rapid increase in the $H$ component (Iijima, 1972; Kawasaki and Meng, 197.3) which is referred to as the positive-bay onset. Since these mid-and low-latitude variations are produced by three-dimensional currents extending into the distant magnetosphere, they are much more reliable signatures of the onset of large-scale magnetospheric substorm effects than are the high-latitude variations, which are produced mainly by localized overhead ionospheric currents. Therefore, in the case of temporally-isolated substorms, which follow reasonably long periods of magnetic quiescence, the low-latitude onsets are expected to be convenient signatures separating a period of time during which the direct effects of the interplanetary-geomagnetic field interaction are readily observable from the succeeding period that is dominated to a large extent by substorm-associated magnetospheric instabilities. Employment of the low-latitude onset time as an ordering parameter by Foster et a1 (1971) has clarified considerably the response of the $\mathrm{AE}$ index to interplanetary $\mathrm{B}_{z}$ variations. Foster and co-workers considered 54 substorms which were isolated in time by at least four hours from other auroral-zone disturbances. These substorms were accompanied by auroral-zone magnetic bays exceeding $200 \gamma$ and either by positive $\mathrm{H}$ bays or by other sharp H or D variations (Meng and Akasofu, 1969; Kawasaki and Meng, 1973) at pre-midnight low-latitude stations. In each case, the sharp onsets of the auroral-zone negative bay and the low-latitude disturbance coincided to within ten minutes. Designating a time midway between the two onsets as $T_{0}$, and identifying this time as the beginning of the expansion phase of an isolated large-scale substorm, Foster et al then 
examined the average behavior of interplanetary $B_{Z}$ for the 54 events. The results are shown in Figure 1. The sharp-onset negative bays which, by definition, began within five minutes of $\mathrm{T}_{\mathrm{O}}$ are apparent in the average $\mathrm{AE}$ plot. Also apparent is the approximately 80 -minute period of gradual $A E$ enhancement which began nearly at the time the average interplanetary $B_{z}$ became negative and which was noted in individual substorms by McPherron (1970) to be a characteristic feature of the substorn growth phase. One should note that the positive excursion of the average $B_{z}$ curve beginning at approximately $\mathrm{T}_{\mathrm{o}}+25$ minutes most probably arises from the isolated nature of the substorms selected.

It is readily apparent in Figure 1 that the result of a cross-correlational analysis performed between the $A E$ and $B_{z}$ curves would result in a peak correlation at an approximate $\mathrm{AE}$ lag of 40 minutes, a time consistent with the resu1ts of Meng et a1 (1973) and Rostoker et a1 (1972). However, in the analysis by Foster et al there is 1ittle of the ambiguity noted by Meng et a1 (1973) concerning the meaning of the lag between the $\mathrm{B}_{z}$ and $\mathrm{AE}$ variations. For the isolated substorms considered in Figure 1 there is, on the average, an 80-minute delay between the southward-turning of the interplanetary magnetic field and the sharp increase of $\mathrm{AE}$. The peak of $\mathrm{AE}$ occurs about 40 minutes later. These substorms presumably were isolated in time because the negative $B_{z}$ component was not maintained at a high leve1 for an extended period. Rather, it began to recover soon. after $T_{o}$, resulting in the beginning of $A E$ recovery approximately 40 minutes later. 
The gradual $\mathrm{AE}$ enhancement began at $\mathrm{T}_{\mathrm{o}}-80$ minutes in Figure 1 , only a few minutes after the southward turning of $\mathrm{B}_{Z}$, and this behavior is consistent with the results of Tsurutani and Meng (1972). In many or a11 of the 54 substorms, sharp-onset negative bays may have occurred during this gradual $\mathrm{AE}$ enhancement in the low polar cap or on isolated meridians where they were undetectable by the existing auroral-zone magnetic instrumentation. However, time $T_{0}$ also marked the time of sharp onset of significant low-latitude nightside disturbances, which reflected the widespread nature of the substorm onsets. Before time $T_{0}$ the interplanetary magnetic field was southward, on the average, for a time of one hour or more. It is this time period which is expected to be dominated by the solar-wind driven and interplanetary-magnetic-field controlled convection as it approaches a new equilibrium state.

As noted by Coroniti and Kennel (1973) and Akasofu and Kan (1973), the changes in large-scale convective flow patterns which occur during periods after the IMF becomes more southward can be understood in terms of a sudden enhancement of antisunward convection across the polar caps combined with a slower increase of the sunward flow rate at lower latitudes. Such adjustments of large-scale magnetospheric flow patterns often can be inferred from phenomena such as ground magnetic variations at polar-cap and equatorial 1atitudes (Nishida and Kokubun, 1971; Kawasaki et a1, 1973), variations in tail-1obe magnetic energy density (Aubry and McPherron, 1971; Nishida and Nagayama, 1973; Meng and Colburn, 1973), and 1atitudinal shifts of dayside auroras and the associated F-layer irregularity zones or FLIZ (Pike et a1, 1973). Quantitative studies of such phenomena as they 
- 14 -

respond to changes in the strength and direction of the IMF are beginning to yield important new information on the nature of the interaction between the interplanetary and geomagnetic fields. 
TAIL-LOBE MAGNETIC VARIATIONS

Iijima (1972) and McPherron (1973) have also employed the technique of keying on the temporally-isolated low-1atitude onset time to confirm and quantify previous results of Fairfield and Ness (1970) and Aubry and McPherron (1971) concerning pre- and post-onset variations of the tail-1obe magnetic energy density. The results of McPherron (1973), which are similar to those of Iijima (1972) are shown in Figure 2. In this figure the average tail-1obe magnetic energy density for 24 isolated substorms is plotted versus time before or after the low-latitude onset time. Before averaging, the energy density curve for each event was normalized to its value at $t=0$. An average increase of about $27 \%$ over quiet levels is evident during the approximately two-hour period before $t=0$. As noted by Caan et a1 (1973a), this corresponds to an average $B$ increase of $14 \%$, a value consistent with the results of Meng and Colburn (1973). Subsequent to the expansion onset the lobe energy density decreased within about one hour to quiet levels which were, on the average, lower than the quiet levels preceding the event. This was due, however, to the orbit of 0G0-5 which was bound down the tail in nearly all the cases considered. In Figure 2 is also shown the corresponding average behavior of interplanetary $B_{z}$. Just as in the $A E$ analysis of Foster et al (1971), the re existed a period of at least one hour prior to $t=0$ in which $B_{z}$ was negative. Reference to figures in Caan et al (1973a) which plot the $-B_{z}$ variations for each of the events reveals that, while the interplanetary magnetic field was generally southward before $t=0$, some cases of fluctuating north-south or nearly horizontal fields did occur. Again, therefore, while the existence of a solarmagnetospheric southward $\mathrm{B}_{z}$ component prior to $t=0$ is confirmed in the 
average behavior, the range of actual magnitudes and directions of the interplanetary magnetic field in individual cases is less easily specified. Recent comprehensive analyses by Meng and Colburn (1973) and Nishida and Nagayama (1972) have confirmed that the increase of tail-1obe magnetic energy density actually begins coherently with sudden southward turnings of $\mathrm{B}_{z}$. Nishida and Nagayama (1973) offer further statistical evidence that the tail-lobe $B$ increase propagates down the tail, appearing at later times as the moon's orbit is approached. 
PLASMA AND MAGNETIC BEHAVIOR NEAR THE NEUT'RAL SHEET

As noted by Meng and Colburn (1973) the magnetic behavior in the plasma sheet is not as easily determined as that in the higher-latitude tail lobes. This difficulty is due chiefly to the diamagnetic effects of the plasmasheet particles. Hones et al (1973) have noted that in substorms that seem to have a development phase, plasma-sheet thinning (at $r \approx 18 R_{E}$ ) is found to start within a few minutes of the beginning of the gradual deepening of magnetic bays at the earth. This thinning simply continues or accelerates after the sharp deepening of the bays characteristic of the expansion phase. In substorms which do not show gradual development, the thinning begins coincident with the sudden bay onset. Although in one wel1-documented case (Hones et a1, 1971 ) the gradual thinning did occur in the presence of a southward interplanetary magnetic field, the possible relationships between the gradual plasma-sheet thinning and the IMF direction have not been studied comprehensively.

A very detailed study of magnetic and plasma variations occurring near the neutral sheet (where the gradual thinning is not clearly apparent) has, however, been conducted by Nishida and Nagayama (1973) and Nishida and Hones (1973). The use of the low-1atitude positive-bay onset as an ordering parameter in these two studies has resulted in an important clarification of the relationship of the formation of macroscopic X-type neutral lines in the tail to substorm temporal development, a relationship suggested by Camidge and Rostoker (1970) and discussed further by Rostoker and Camidge (1971). The study of Nishida and Nagayama (1973) indicates that a macroscopic neutral line is formed within 10 minutes of the low-latitude positivebay onset in the neutral sheet at distances of 15 to $25 R_{E}$ down the tail. 
The neutral-1ine formation was inferred from the appearance of southward $\bar{B}$ components near the neutral sheet and within $15 \mathrm{R}_{\mathrm{E}}$ of the midnight meridian. Consistent behavior was seen out to distances of $65 \mathrm{R}_{\mathrm{E}}$ down the tail, with the southward component persisting for times of about one hour. Inside $15 \mathrm{R}_{\mathrm{E}}$, however, $\mathrm{B}_{\mathrm{z}}$ increased at the expansion onset, reflecting a behavior similar to that seen at the earth's surface. The appearance of the southward component out to the orbit of the moon indicates that at these times reconnection is occurring on the open field lines of the tail lobes. If the reconnection involved only closed field lines threading the plasma sheet one would expect closed loops to form, producing an 0-type neutral line at greater distances down the tail (Akasofu and Chapman, 1961; Russe11, 1973), and this has not been observed by Nishida and Nagayama (1973) to occur at the time of low-latitude onset. On the other hand, since first observed by Mihalov et a1 (1968) and Sonett et al (1968), the sporadic occurrence of shorter-duration southward $B_{z}$ near the neutral sheet has been found to be common even during quiet times. This turbulent internal structure of the neutral sheet was found by Schindler and Ness (1972) to be consistent with the formation of closed loops of the type expected for reconnection involving closed field lines. Figure 3 shows schematically the idealized topologies for reconnection on closed field lines, resulting in closed loops, and reconnection on open field lines, resulting in a macroscopic X-type neutral line configuration. Akasofu (1973) has suggested that reconnection in the tail could be responsible for the inverted ' $V$ ' events described by Frank and Ackerson (1972) and Gurnett and Frank (1973), which occur 
poleward of the 40-kev trapping boundary and chiefly in the evening sector. The existence at all times of the inverted ' $V$ ' bands; and the frequent existence of multiple bands in a single latitudinal scan, may be understandable in terms of the configuration shown in Figure 3 . That is, the closed loops and the macroscopic $X$-type neutral line may be the sources of the inverted ' $\mathrm{V}$ 's and may define the distant plasma sheet which Frank (1973) has suggested as a possible source region. Earthward of the closed-1oop reconnection region a trapped distribution of plasma-sheet particles could be maintained, while poleward of the macroscopic neutral line, no particle precipitation would be expected.

Russe11 (1973) has suggested that spatially-isolated substorms may be associated with the closed-1oop type of reconnection occurring within the plasma sheet. This isolated substorm may then develop into a largescale substorm as reconnection works its way onto open field lines, producing a macroscopic $\mathrm{X}$-type neutral line configuration. Any closed loops existing beyond this newly-formed neutral line would be convected down the tail. This possibility is also sketched figuratively in Figure 3 . Evidence in support of this suggestion that $\mathrm{X}$-type neutral line formation in the near-earth plasma sheet is associated with large-scale substorm onsets has been presented by Nishida and Hones (1973).

Figure 4, which is taken from the study of Nishida and Hones (1973), provides an example of the negative $B_{z}$ transitions from which Nishida and Nagayama (1973) deduced the formation of $\mathrm{X}$-type neutral lines between the earth and the observing position (in this case at $31 R_{E}$ down the tail). Note that the interplanetary $B_{z}$ was negative (or southward) and the tail 
$B_{z}$ gradually decreased as the tail become distended for a period of about $1 \frac{1}{2}$ hours before the onset of the 1ow-latitude positive bay at the nearmidnight station Huancayo. However, the electron pressure at a Vela satel1ite showed no effects of plasma-sheet thinning until about 15 minutes before the appearance of negative $B_{z}$ at IMP-F. In this example the negative $B_{z}$ persisted for about one-half hour, while the reappearance of the plasma sheet at the vela position, $4 \mathrm{R}_{\mathrm{E}}$ above the expected neutralsheet location, was delayed by another hour. On the other hand, whenever Vela was within $2 \mathrm{R}_{\mathrm{E}}$ of the neutral sheet the plasma-sheet thinning and thickening was typically observed by Nishida and Hones to be nearly coincident with the beginning and end, respectively, of the southward tail field.

In the example of Figure 4, localized negative bays are not apparent in the auroral-zone magnetograms displayed until the time of the positivebay onset at low latitudes. This is not always the case, however. The question of whether the more localized substorms are associated with reconnection on closed field lines, as suggested by Russel1 (1973), or with the collapse of the stressed tail field and the formation of an X-type neutral line over a limited longitudinal sector of the tail as suggested by Rostoker and Camidge (1971), has not been answered by the studies of Nishida and Nagayama (1973) and Nishida and Hones (1973). They have established, however, that the near-midnight positive-bay onset at low latitudes is an important tempora1 signature which is associated with the onset of impulsive behavior, including $\mathrm{X}$-type neutral-line formation inside the Vela orbit and rapid plasma-sheet thinning resulting from strong plasma flow down the tail (Hones, 1973). This behavior appears to be unrelated to any signature in the interplanetary magnetic field. 
DAYSIDE FLUX EROSTON AND EXPANSION OF THE POLAR CAP

The studies of Caan et al (1973a, 1973b), Meng and Colburn (1973) and Nishida and Nagayama (1973) have established that a southward-turning interplanetary magnetic field produces an almost immediate $10-15 \%$ increase of the magnetic energy density in the lobes of the tail. In addition, Caan et al (1973b) have separated this effect from that due to increases in the solar-wind kinetic energy flux. There being no evidence for an associated decrease of the cross-sectional area of the tail, while pressure-balance considerations suggest that the tail may actually flare to a larger area during these increases (Siscoe and Cummings, 1969; Coroniti and Kenne1, 1973), we can conclude that the total magnetic flux through a cross-section of the tail is increased. Simple flux conservation requires that such an increase be accompanied by a decrease of total dayside magnetic flux and a lowering of the latitude of the last closed dayside field line. This effect is illustrated by the solution of Unti and Atkinson (1968) and Atkinson and Unti (1969) to the two-dimensional Chapman-Ferraro problem for various tail magnetic field strengths. Results from this study are shown in Figure 5. As the tail field strength is increased. through the three levels indicated, the pressure-balance calculations result in a progressive shrinking of the dayside magnetosphere and flaring of the tail. The accumulating evidence that magnetospheric reconfigurations of this type do occur when the IMF becomes more southward, and comparisons of quantitative studies of the reconfigurations with recent merging mode1s are the subjects of this section.

That the dayside magnetopause tends to locate closer to the earth during substorm activity registered by the $\mathrm{AE}$ index was established by 
Meng (1970). A subsequent statistical study by Fairfield (1971) showed that the more earthward magnetopause positions are associated with southward interplanetary magnetic fields. The only direct observation of the actual inward motion, on March 27, 1968, was described by Aubry et a1 (1970). In this single event, which has been discussed extensively in the literature (e.g., Russell and McPherron, 1973b; Russel1 et al, 1973) OGO-5 crossed the magnetopause repeatedly in its inbound orbit. The bulk of the inward motion, amounting to about $2 \mathrm{R}_{\mathrm{E}}$ occurred prior to the first appearance, at 1855 UT at Dixon Island, of a sharp negative-bay onset in the auroral zone. Furthermore, the fact that the inward motion commenced at $\sim 1730 \mathrm{UT}$, soon after the interplanetary magnetic field turned southward; indicated strongly that the southward IMF was the chief cause of the magnetopause displacement. Again, this does not mean that undetected substorms did not occur during the initial inward motion. This possibility is particularly germane in view of the important discovery by Akasofu et a1 (1973) of auroral substorms along a contracted oval which is poleward of most auroral-zone stations. Measurements of solar-wind plasma by a vela satellite during the period of the magnetic observations of Aubry et al (1970) showed further that the observed inward motion of the magnetopause was not accompanied by an increase of the proton kinetic energy flux. Aubry and co-workers concluded that only through a postulated increase of the relative helium component of the solar wind to an unrealistically high level of $30 \%$ could the observed magnetopause displacement be explained by a compression of the magnetosphere. They suggested instead that magnetic flux had been transferred or eroded from the dayside to the nightside and that a new 
pressure balance between the solar wind and the magnetosphere was set up closer to the earth in a manner qualitatively similar to the results of Unti and Atkinson (1968) referred to above. The displacement observed by Aubry et a1 requires a decrease of the field strength of about $17 \gamma$ just inside the original magnetopause position. Russell et al (1973) have noted that this decrease is too great to be explained by the edge effects of an intensified neutral-sheet current associated with observed tail field increases. Furthermore, the field strength just inside the displaced magnetopause was some $20 \%$ higher than that inside the original magnetopause, raising the question of how pressure balance was maintained at the two locations with no change in solar-wind plasma pressure. Russe11 et a1 (1973) have noted that part of this discrepancy may be due to a difference in the direction of magnetopause normals at the two locations. Such questions emphasize the importance of obtaining more data on individual erosion events and of developing theoretical models of the associated magnetospheric current systems such as discussed by Coroniti and Kennel (1973).

Nevertheless, there is little doubt that a net transfer of magnetic flux from the dayside to the nightside occurs in conjunction with southward interplanetary magnetic fields. However, such a transfer is not of necessity caused by merging of interplanetary and geomagnetic field lines. Any process that increases the total magnetic flux in the tail lobes necessarily results in erosion of magnetic flux from the dayside as defined by Aubry et al (1970). 
The aforementioned facts that, (1) convection is always occurring in the magnetosphere, (2) the flow across the polar caps is under almost all conditions antisunward, that is, consistent with a dawn-dusk electric field across the magnetosphere, and (3) the asymmetries of the polar-cap convective flow are determined by the direction of the interplanetary magnetic field, provide some important clues concerning the process that is responsible for erosion. We know, therefore, that plasma and frozen-in magnetic field lines are continually being carried across the polar caps and eventually returned to the dayside by internal magnetospheric convection. As noted by Coroniti and Kennel (1973), erosion simply requires the development of a temporary imbalance between the rate of antisunward convection and the rate of sumward convection, not a change in the basic driving mechanism.

Support for this view is provided by Nishida and Kokubun (1971) and Kawasaki and Akasofu (1973), who noted that the $\mathrm{S}_{\mathrm{q}}$ or polar-cap solar quiet day current system is basically the same during very quiet periods and as activity increases. This current system is thought to be a manifestation of convection in the polar cap ionosphere, while its enhancement during periods of southward IMF and the associated world-wide effects have been referred to as DP2 activity by Nishida and Maezawa (1971). Viscous interactions may be responsible for erosion if in some way they can be shown to intensify when the IMF is southward, and Cassen and Szabo (1970) have described certain conditions under which this may happen. The interplanetary electric field does have a dawn-dusk component when interplanetary $B_{z}$ is negative. However, a direct penetration of this electric field 
into the magnetosphere must be ruled out, since positive $B_{z}$ values would imply sunward convection over the polar caps, and this is not normally observed (Heppner, 1972; Mozer et a1, 1973). On the other hand, recent reconnection models of the open magnetosphere proposed by Stern (1973) and Gonzalez (1973) do produce magnetospheric electric fields which are always in the dawn-dusk direction and which are most intense when the IMF is southward. At present, then, the most reasonable explanation for erosion involves an increase in the merging rate between the interplanetary and geomagnetic fields and the subsequent transition toward a new equilibrium state. In the final configuration, the increased dayside merging rate is matched by a higher rate of reconnection across the neutra1 sheet. Unsteady convection is, of course, involved during the large-scale magnetospheric reconfiguration which occurs during the erosion process. The role of the ionosphere in this process has been discussed by Coroniti and Kenne1 (1973), Reid and Holzer (1973), and Holzer and Reid (1973). As noted in the paper by $\underline{\text { Burch }}(1973 \mathrm{~b})$, low-altitude measurements of the latitude of the last closed field line on the dayside are well-suited for the quantitative determination of variations of total dayside magnetic flux. That the high-altitude polar cusp moves equatorward and poleward in response to southward and northward IMF transitions has been confirmed by Russe11 et al (1971) from OGO-5 measurements during the magnetic storm of November 1, 1968. At 1ower altitudes Burch (1972b) has reported that the low-1atitude boundary of polar-cusp electron precipitation moves equatorward by several degrees during substorms and, in the absence of substorm activity, during a period when the IMF is southward. This behavior has been confirmed by Yasuhara et a1 (1973) for both the equatorward 
and poleward boundaries of polar-cusp proton precipitation. The equatorward boundary for precipitation of these charged particles of magnetosheath origin, in the approximate magnetic-local-time range of 9-15 hrs, is presently interpreted as being either coincident with, or bearing a constant relationship with the last dayside closed field line. Relative variations of the latitude of this boundary can, therefore, be used to estimate fairly accurately quantitative variations in the total amount of magnetic flux in the dayside magnetosphere. Measurements from polarorbiting satellites, however, have a serious drawback in that determinations of the latitude of the last closed field line are obtained only twice per orbit. Ground-based observations of dayside auroras (Akasofu, 1972) and F-layer ionization irregularities (Snyder et a1, 1973) therefore offer the greatest potential for future studies.

To date, however, the only quantitative relationship between the direction and magnitude of the IMF and the latitude of the last closed field line which has been obtained has employed polar-orbiting satellite data (Burch, 1973b). In that study, use was made of previous results (Burch, 1972b) that the latitude of the last closed field line is determined chiefly by the angle between the earth's dipole axis and the earthsun line and the magnitude and duration of IMF southward components. That is, for periods of northward IMF the statistical latitude of the equatorward boundary of polar-cusp electron precipitation was found to be approximately $74^{\circ}, 77^{\circ}$, and $78^{\circ}$ for winter solstice, equinox and summer solstice conditions respectively. Following sharp transitions to southward IMF components, the cusp location was found at progressively lower 
latitudes as the time between the southward-turning and the satellite traversa1 of the cusp increased. As noted by Coroniti and Kenne1 (1973), the enhanced antisunward convection which apparently begins soon after a southward IMF transition will eventually be balanced by sunward convection on closed field lines as the imitial effects of ionospheric linetying are overcome. The rates of antisunward and sunward convection should then equalize, after which time the amount of magnetic flux in the dayside magnetosphere would remain approximately constant for as long as the IMF maintains a constant magnitude and direction, Coroniti and Kenne1 (1973) estimated an exponential time constant of 20 minutes for the growth and decay of sunward convection in response to southward and northward turnings of the IMF. Thus, an appropriate time scale for relating average IMF behavior to the latitude of the last closed field line is approximately two time constants since earlier IMF variations would be largely "forgotten" by the magnetosphere. The results of Burch (1973b) are displayed in Figure 6, in which the latitudes of the equatorward and poleward boundaries of polar-cusp electron precipitation are plotted versus the average IMF southward component for the previous 45 minutes. Times of 15,30 and 60 minutes were also used but resulted in somewhat poorer correlation. The solid lines are second-order fits to the data.

We note in Figure 6 that as the average IMF southward component increases, the polar cusp is found at progressively lower latitudes while maintaining its approximate $1 y 4^{\circ}$ width. On the other hand, the poleward movement of the equatorward boundary slows considerably as $\mathrm{B}_{z}$ becomes 
more positive, resulting in a width of nearly $7^{\circ}$ for strong northward IMF's.

Further evidence that this statistical widening of the cusp during periods of strong northward IMF occurs in individual cases is presented in Figure 7. In this figure the data of Figure 6 are replotted and connected by solid lines for all cases when near-simultaneous measurements of the equatorward and poleward boundaries of cusp electron precipitation were made during single 0G0-4 passes. The dashed vertical lines indicate latitudinal widths of proton cleft precipitation as determined from ISIS-1 data and kindly provided by Dr. J. D. Winningham. Although a wide variation of latitudinal widths is apparent, it is evident that instances of very large cusp latitudinal widths are confined to periods when interplanetary $B_{z}$ is significantly positive or northward. This behavior was interpreted by Burch (1973b) as possibly resulting from merging between the IMF and geomagnetic-tail field lines, which are directed southward near the dayside magnetopause. This suggestion is essentially equivalent to the northward-IMF reconnection model of Dungey (1963). The effects of such a reconnection mode1 should also be observable in the boundary layer plasma which has been described by Hones et a1 (1972) and Rosenbauer et a1 (1973).

If, in the northward reconnection model, individual interplanetary field lines become connected both to the northern and southern hemispheres, the polar-cusp field lines would be closed and perhaps able to provide drift paths for energetic magnetospheric particles that otherwise would have drifted through the magnetopause. Such a picture is qualitatively 
consistent with the observations of Kivelson et al (1973) who detected energetic (> $50 \mathrm{kev}$ ) electrons in the polar cusp only when the IMF was northward.

Concerning the sources of scatter for the data points in Figure 6 , the following comments should be made. (1) The range of dipole tilt angles included produce an expected scatter of $2^{\circ}$ (Burch, 1972b).

The scatter due to differences between the measured IMF and that affecting the magnetosphere was minimized by requiring that the IMF measurement be made within $12 \mathrm{R}_{\mathrm{E}}$ of the earth-sun line and at $\mathrm{X}_{\mathrm{GSM}}$ coordinates less than $31 \mathrm{R}_{\mathrm{E}}$. Several investigators $(G \cdot \mathrm{K}$. Parks and R. L. McPherron, persona1 communications) have noted the fairly common occurrence of vastly different IMF directions measured from two spacecraft in the general vicinity of the earth. (3) The dayside aurora observations of Akasofu (private communication) often exhibit a very rapid equatorward movement coincident with the maximum epoch of nightside polar magnetic substorms. This rapid movement may only involve the motion of individual arcs within the polar cusp, or it may involve an actual rapid equatorward movement of the cusp low-latitude boundary. The latter possibility would definitely contribute to the scatter in Figure 6 and would also indicate flux transfer not ascribable to the southward IMF alone. This question is resolvable by coordinated observations of dayside discrete auroras and the total zone of F-layer ionization irregularities as have been reported by Pike et al (1973).

Electron precipitation measurements by Hoffman and Burch (1973) and coordinated airborne al1-sky camera and ionospheric sounder 
observations by Pike et al (1973) have indicated that the nightside portion of the auroral oval also moves equatorward during periods of southward IMF along with the dayside portion of the ova1, or the lowaltitude extension of the polar cusps. The very high latitude oval that exists when the IMF is northward has been termed the contracted auroral oval by Akasofu et al (1973). Owing to the present sparsity of observing stations at latitudes above about $70^{\circ}$, very little is known about possible changes in the size of this contracted oval as the IMF strength and direction varies within the northward range. The Air Force DAPP photographs should, however, provide a wealth of information on this subject in the very near future. A few observations of substorms along the contracted oval have been made by Akasofu et a1 (1973) using the Alaska meridian magnetometer and al1-sky camera chain. An example of a contracted-oval magnetic substorm as defined by Akasofu et al (1973) is shown in Figure 8.

The example of Figure 8 satisfies the definition of Akasofu et al (1973) for contracted-oval substorms. That is, substorm magnetic variations are evident at the $\Lambda \geq 70^{\circ}$ stations in the chain but not at the auroral-zone station College. Akasofu et al (1973) presented four examples of contracted oval substorms that occurred when the Alaska meridian chain was near enough to midnight to give reasonable discrimination against substorm effects which actually occurred at lower latitudes but were not detected by the chain. The IMF directions which Akasofu et al presented in solar-equatorial coordinates were either nearly horizontal or in the northward range for these four cases, a 
behavior which led them to conclude that the occurrence of substorms does not depend on the IMF direction. Figure 9 shows the corresponding IMF 1 atitude in solar-magnetosheric coordinates which, as noted above, appear to be more appropriate for the study of the interplanetary-geomagnetic field interaction. For each of the four cases, the IMF latitude is plotted versus time before and after the onset time, $T_{0}$, of the contracted-oval substorms as defined by Akasofu et al (1973). The data of Figure 9 indicate that, at least for the four cases available, the IMF latitude was general1y in the rather narrow range of $0^{\circ}-30^{\circ}$ for a period of about one-half hour before $T_{0}$. It is possible that the aurora1 oval contracts even further for IMF latitudes significantly more northward than this range. Alternatively, this may be the IMF latitude range which is statistically related to substorm occurrence in the contracted oval just as southward IMF latitudes are associated with substorms at lower latitudes in the classical auroral zone.

Returning to Figure 6 , we note that the statistical equatorward motion of the low-latitude cusp boundary, or last closed field line, begins for average IMF $\mathrm{Z}$ components less than about $2 \gamma$, corresponding to average latitudes of $20-25^{\circ}$. It therefore appears that erosion of dayside magnetic flux begins to occur when the IMF is slightly northward, that is, when conditions are similar to what they were before the four contracted-oval substorms identified by Akasofu et a1 (1973). In terms of the open magnetosphere this may indicate that as the dayside merging efficiency begins to increase significantly substorms become more likely along the contracted auroral oval. As discussed below, recent models 
of the merging process for unequal magnetosheath and magnetospheric fields support the conclusion that merging efficiency does in fact begin to increase significantly as the IMF latitude decreases into the slightly northward range.

It is appropriate to recal1 here that dayside merging is not as we11 established by in situ measurements of the associated magnetic field perturbations and plasma flow as is the substorm-associated merging through the $\mathrm{x}$-type neutral line configuration in the tail. This is partly due to the rather sparse satellite coverage of the magnetopause compared to the extensive measurements which have been made in the plasma sheet. It may also result to some extent, however, from the greater complexity of the magnetopause plasma and field structures. That is, for merging across the neutral sheet the fields on either side of the merging region are always nearly antiparallel and the plasma densities on either side are nearly equal. Although the process which initiates reconnection in the tail is not understood, we do know that it begins at substorm onset perhaps through a sudden decrease in the local plasma density through precipitation or some other disruptive process resulting in the vacuum merging situation suggested by Desslex (1971). On the other hand, as pointed out by Russell et al (1973) the postulated merging region at the dayside magnetopause has not clearly been identified although Sonnerup (1971) has on two occasions observed rotational discontinuities at the dayside magnetopause which were consistent with a near-subsolar neutral line. Moreover, the merging in this region is more difficult to model theoretically since inside the magnetopause the field strength is higher 
and the plasma density much lower than in the magnetosheath, and a11 relative orientations of the two magnetic fields are possible. Nevertheless several models of the interaction there have been proposed.

As interplanetary magnetic field lines approach the magnetopause they are forced against it in a manner predicted by Levy et al (1964) and confirmed by Fairfield (1967). This generally results in a decrease of any existing radial component but no change in the direction of the field in the dawn-dusk plane. As the magnetosheath plasma flows around the magnetosphere, the IMF field lines must either slip around it or become connected with magnetospheric field lines. As suggested by Levy et al (1964) some fraction, as determined by the merging rate, will interconnect while the others will slip sideways around the magnetosphere. Levy et a1 (1964) also noted that, since the magnetosheath plasma can bypass the magnetosphere by flowing along the field lines, there will be a pile-up of field lines at the subsolar magnetopause. The resulting increase of field strength has been observed by Fairfield (1967) and others. Generally, then, while pressure balance is maintained, the re1 ative contribution of magnetic pressure is enhanced in this region. Alfvén. (1968) and Al fvén and Falthammer (1971) have considered the formation of a self-consistent neutral sheet at the dayside magnetopause as due-southward IMF field lines approach it. Although no direct merging occurs in this mode1, the interplanetary electric field accelerates particles in the $\pm Y$ direction in the field-reversal region, where $B$ vanishes. This conversion of electromagnetic energy to particle energy can be viewed as annihilation of magnetic energy in the neutral sheet. 
Hill (1973) has generalized this model to arbitrary non-radial IMF directions. Hill also noted that, while merging does not occur in. the interaction region, it must occur just outside it, perhaps near the polar cusps, to provide topological continuity of field lines. Realistic values of magnetic field strengths and particle densities result in very slow field-annihilation rates and less than a $10 \mathrm{Kv}$ potential across the magnetosphere (Hill, 1973; Alfvén and Falthammer, 1971). At present this neutral-sheet model appears to fall far short of predicting the merging rates and magnetospheric electric-field magnitudes which have been observed. It remains, however, the on $1 y$ quantitatively accurate model of the interaction since the reconnection models discussed below require assumptions concerning possible merging speeds.

That rapid merging may occur through $\mathrm{x}$-type neutra1-line configurations was pointed out by Petschek (1964), who noted that merging fie1d 1ines would consitute rotational discontinuities, which can rapidly propagate as Alfvén waves away from the merging region. Subsequent calculations by Levy et al (1964), Sonnerup $(1970,1973 a)$ and Yeh and Axford (1970) employed this concept. Briefly, in these models the frozen-in-flux condition is satisfied everywhere except in a diffusion region surrounding the neutral 1ine. Ultimately, the efficiency or speed of merging must be determined by the dissipative processes such as microscopic turbulent resistivity (Sonnerup, 1973a) at work in the diffusion region. Yeh and Axford (1970) have noted, however, that whatever processes occur in the diffusion region, its physical size will be the most important factor. Since the size of the diffusion region may largely be controlled by 
hydromagnetic pressure gradients which are determined by conditions far from the diffusion region, Yeh and Axford (1970) have suggested that, depending on boundary connections, merging can proceed at arbitrary speeds up to the order of the local Alfvén velocity $\left(v_{A}\right)$.

Although the question of how merging speeds are limited in the diffusion region is far from being answered, the applicability of the frozen-in-flux approach in regions away from the neutral line has been employed by Sonnerup (1973b) and Gonzalez (1973) in deducing relative changes in the merging rate for varying magnitudes and directions of magnetosheath and magnetospheric field lines. In Dungey's due-south IMF and dipole field model there is an equatorial neutral line at which $B$ vanishes. Stern (1973) and Cowley (1973) have noted, however, that when the IMF field lines possess dawn-dusk components only two neutral points are formed in this type of mode1. Figure 10 is taken from the paper by Stern (1973). Figure 10a is a view from the sun that shows the result in the dawn-dusk meridian of adding a uniform IMF pointing toward dusk to a dipole model of the geomagnetic field. For this configuration the solar-wind electric field $(\overline{\mathrm{E}}=-\overline{\mathrm{v}} \times \overline{\mathrm{B}})$ is directed northward and two neutral points are formed, at dawn in the southern hemisphere and at dusk in the northern hemisphere. If the solar-wind electric field maps along the field lines through these neutral points a dawn-dusk electric field will be produced across both polar caps. The situation when the IMF points toward dawn is shown in Figure 10b. Again, two neutral points are formed and the electric field across the polar cap is directed dawndusk. The neutral points are connected by a line of symmetry along 
which the IMF and magnetospheric field 1 ines have equal components. This line of symmetry separates regions of closed and open field lines. As noted by Petschek (1966), Sonnerup (1973b) and Gonzalez (1973), reconnection is expected to occur along this line involving any antiparallel magnetospheric and magnetosheath $\bar{B}$ components perpendicular to it. Sonnerup (1973b) and Gonzalez (1973), have noted that these components are antiparalle 1 only when $\cos \theta<\frac{B_{0}}{B_{i}}$, where $\theta$ is the angle between the two field lines and the subscripts $o$ and $i$ refer to outside and inside the magnetopause.

The results of Sonnerup (1973b) are shown in Figure 11 for various ratios of the magnetic field outside and inside the magnetopause. In Figure 11 the normalized potential across a reconnection region of width $D$ is plotted versus the angle between the two magnetic field vectors. The quantity $k$ is the fraction of the magnetosheath Alfvén velocity at which reconnection can proceed. This quantity must be a significant fraction of unity if the reconnection mode1s are to explain the observed potentials across the polar cap. For the rather typical situation in which $\mathrm{B}_{\mathrm{o}} / \mathrm{B}_{i}=0.5$, Figure 11 indicates that merging becomes geometrically impossible when the angle between the two fields falls below $70^{\circ}$. This corresponds to interplanetary fields more northward than about $30^{\circ}$ near the subsolar point, and is in reasonable agreement with the results of Figure 6.

As a final point we note that the data of Figure 6 can a1so be used to estimate the ratio between the average amount of solar-magnetospheric southward magnetic flux approaching the magnetosphere in the undisturbed 
solar wind to. the amount of flux eroded from the dayside as deduced from the equilibrium displacement of the cusp lower boundary from a reference latitude of $76.5^{\circ}$. This ratio, which ignores the effects of internal magnetospheric convection was calculated by Burch (1973b) to be .092 . Burch (1973) has noted that according to the model of Coroniti and Kenne 1 (1973), this ratio should be approximately doubled to account for the. effects of return of magnetic flux to the dayside by convection. Although the solar-wind flow is decelerated near the subsolar magnetopause, the interplanetary electric field magnitude should remain constant away from the diffusion region surrounding the postulated $\mathrm{X}$-type neutral 1 ine. Therefore, for the simple case of a due-southward IMF, the deceleration. should be nearly matched by an increase in $B$, resulting in a constant flow of magnetic flux toward the magnetopause. One can, therefore, estimate that in such a situation $18 \%$ of the magneosheath field lines merge with the geomagnetic field while the rest slip around the magnetosphere. In terms of merging speeds, a solar-wind velocity of $450 \mathrm{~km} / \mathrm{s}$ (used in the paper by Burch, 1973) would imply a merging speed of (.18) 450 or $81 \mathrm{~km} / \mathrm{s}$. This compares to an Alfvén speed of about $210 \mathrm{~km} / \mathrm{s}$ for the typical subsolar magnetosheath parameters $B=30 \mathrm{\gamma}$ and $n=10$ ions/ $\mathrm{cm}^{3}$. Merging speeds on the order of the Alfvén speed are, therefore, not ruled out by these measurements.

A reconnection model similar to that of Sonnerup (1973b) has been used by Gonzalez (1973) to predict quantitatively the potential across the polar cap. These predictions agree within a factor of two with local electric field measurements made from balloons in the polar cap stratosphere. This comparison is shown in Figure 12, which is taken from the 
paper by Mozer and Gonzalez (1973). Hourly averages of the three cartesian components of the IMF are shown along with the measured electric field at Thule and Resolute Bay and the computed electric field. Corresponding behavior has not as yet been observed in the outer magnetosphere, although Heppner (1973) has noted in his polar-orbiting OGO-6 measurements a tendency toward higher total polar-cap potentials when the IMF is southward. 
THE INTERPLANETARY MAGNETIC FIELD AND RING-CURRENT DEVELOPMENT

The relationship between ring-current injection and substorm activity was pointed out by Davis and Parthasarathy (1967), who noted that Dst depressions exhibited a temporal behavior similar to substorm $\mathrm{AE}$ variations but lagging them by one or more hours. The close relationship between $\mathrm{AE}$ and the interplanetary magnetic field has since been established and has raised the still unanswered question of to what extent the ring current can develop as a result of a southward IMF in the absence of substorm activity. The observations of Russell et al (1973) and Kane (1973) that $\mathrm{AE}$ is more faithful than Dst in its response to IMF southward turnings may in fact render the question unanswerable using only interplanetary and ground-based $\mathrm{AE}$ and Dst observations. That is, significant ring current development may require IMF southward components of magnitudes and durations sufficient to trigger large substorms with a probability approaching unity.

Nevertheless, that ground-based Dst values can be quantitatively related to the dawn-dusk component of the interplanetary electric field when the solar-wind density and velocity are known has recently been demonstrated by Burton et al (1973). In the Burton et al study, interplanetary observations during ten magnetic storms were used to derive an empirical expression for the rate of change of Dst which includes the effects of changing solar-wind dynamic pressure, an estimated ring-current decay constant, and a main-phase development rate which is proportional to the square of the dawn-dusk component of the interplanetary electric field, while lagging it by one-half hour. An example of the agreement 
between the empirically-determined and actual Dst values is shown in Figure 13, which is taken from Burton et al (1973). In this classic sudden-commencement storm, there is very good agreement between the calculated and observed Dst values except during the protracted recovery phase when the calculated Dst exhibits a more rapid decay. This discrepancy results from the use of a single decay term which apparently is appropriate only for the shorter-time-gale Dst variations.

Observations of the injection or convection of energetic plasmasheet particles toward ring-current orbits in correlation with interplanetary magnetic field variations should eventually resolve the question of whether or not the necessary conditions for ring-current injection obtain in the absence of large-scale substorm activity. Parks and Pellat (1972) and Wehrenberg and Parks (1973) have noted the appearance of energetic electrons at synchronous orbit associated with sudden increases of the dawndusk component of the interplanetary electric field. This observation provides some support for the empirical Dst relation of Burton et a1 (1973), although substorm activity was not ruled out in either study. On the other hand, McIlwain (1973) has noted the injection of plasma sheet particles at synchronous orbit to be generally associated with the onset of substorms. 
SUMMARY

This paper has dealt chiefly with the response of the magnetosphere to variations in the north-south component of the interplanetary magnetic field. This response involves large-scale gradual reconfigurations of the magnetosphere which can best be understood in terms of convection of magnetospheric plasma driven by merging between interplanetary and geomagnetic field lines at the dayside magnetopause. The merging rate apparently increases rapidly when the interplanetary magnetic field turns southward. Reconnection of geomagnetic field lines across the tail neutral sheet allows magnetospheric plasma to convect back toward the dayside. This reconnection often occurs impulsively in association with macroscopic tail instabilities during substorms. The unsteady nature of tail reconnection and the choking of convective flow by magnetic-field gradients and ionospheric dissipation results in a buildup of magnetic energy density in the lobes of the magnetotail. This net transfer of flux from the dayside to the nightside is evidenced by an earthward motion of the dayside magnetopause and an equatorward motion of the polar cusps. Quantitative evaluation of the cusp position has indicated that merging rates approaching the Alfvén velocity are feasible.

The magnetospheric reconfigurations associated with southward interplanetary magnetic fields are largely dominated by substorm effects after the onset of low-latitude positive bays. Prior to this onset time, only localized substorm-associated disruptions of the reconfigurations occur. Aurora1 and magnetic substorms along the auroral oval require the type of magnetospheric reconfigurations that result from southward or nearly 
horizontal interplanetary magnetic fields. Substorm triggering itself is generally not associated with interplanetary variations. However, substorms which occur during periods of northward IMF affect only a contracted auroral oval (Akasofu et al, 1973) in the low polar cap. These substorms certainly involve much less total energy than those that occur at lower latitudes after the buildup of excess magnetic flux in the tail. Other phenomena that are definitely not caused directly by the interaction with the IMF are (1) the formation of macroscopic X-type neutral lines in the tail inside $35 \mathrm{R}_{\mathrm{E}}$, and (2) the rapid thinning of the plasma sheet to near zero thickness. Gradual thinning of the plasma sheet may, however, result directly from the interaction, although this has not yet been confirmed.

\section{ACKNOWLEDGMENTS}

I am grateful to Drs. A. J. Dessler, S.-I. Akasofu and C. T. Russe11 for critically reviewing an earlier version of this manuscript. 


\section{REFERENCES}

Akasofu, S.-I., Polar and magnetospheric substorms, D. Reidel Publishing Co., Dordrecht-Ho11and, 1968. Akasofu, S.-I., Midday auroras at the south pole during magnetospheric substorms, J. Geophys. Res., 77, 2303, 1972.

Akasofu, S.-I., The aurora and the magnetosphere: The Chapman Memoria1 Lecture, Boulder, Colo., 1973.

Akasofu, S.-I, and S. Chapman, A neutral line discharge theory of the aurora polaris, Phi1. Trans. Roy. Soc. A, 253, 359, 1961.

Akasofu, S.-I., and J. R. Kan, Some new thoughts on magnetospheric substorms, Radio Science, $\underline{8}, 1049,1973$.

Akasofu, S.-I., P. D. Perreault, F. Yasuhara, and C.-I. Meng, Aurora1 substorms and the interplanetary magnetic field, J. Geophys. Res., $\underline{78}$, $7490,1973$.

Alfvén, H., Some properties of magnetospheric neutral surfaces, J. Geophys. $\underline{\text { Res. }}$ 73 $, 4379,1968$.

Alfvén, H., and C.-G. Fälthammar, Cosmical Electrodynamics, 2nd edition, Oxford University Press, 1963.

Alfvén, H., and C.-G. Fälthammar, A new approach to the theory of the magnetos phere, Cosmic Electrodyn. , 2, 78, 1971.

Arnoldy, R. L., Signature in the interplanetary medium for substorms, J. Geophys. Res., 76, 5189, 1971 . Atkinson, G., A theory of polar substorms, J.Geophys. Res., 71, 5157, 1966. Atkinson, G., Magnetospheric flows and substorms, in Magnetosphere-Ionosphere Interactions, ed. by K. Folkestad, 203-216, Universitets forlaget, 0s 1o; 1972 . 
Atkinson, G. and T. Unt1, Two-dimensiona1 Chapman-Ferraro problem with neutral sheet, 3, implied magnetospheric flows and their time dependence, J. Geophys. Res., 74, 6275, 1969.

Aubry, M. P., and R. L, McPherron, Magnetotail changes in relation to the solar wind magnetic field and magnetospheric substorms, J. Geophys. Res., 76, 4381,1971 .

Aubry, M. P., C. T. Russell, and M. G. Kivelson, On inward motion of the magnetopause preceding a substorm, J. Geophys. Res., 75, 7018, 1970 . Axford, W. I., Magnetospheric convection, Rev. Geophys. and Space Phys., $\underline{7}, 421,1969$.

Axford, W. I., and C. O. Hines, A unifying theory of high-latitude geophysical phenomena and geomagnetic storms, Can. J. Phys., 39, 1433, 1961.

Ballif, J. R., D. E. Jones, and P. J. Coleman, Jr., Further evidence on the correlation between transverse fluctuations in the interplanetary magnetic field and Kp, J. Geophys. Res., 74, 2289, 1969.

Burch, J. L., Preconditions for the triggering of polar magnetic substorms by storm sudden commencements, J. Geophys. Res., 77, 5629, 1972a. Burch, J. L., Precipitation of low-energy electrons at high latitudes: Effects of interplanetary magnetic field and dipole tilt angle, I. Geophys. Res., 77, 6696, 1972b.

Burch, J. L., Effects of interplanetary magnetic sector structure on auroral zone and polar cap magnetic activity, J. Geophys. Res., 78 , $1047,1973 \mathrm{a}$. 
Burch, J. L., Rate of erosion of dayside magnetic flux based on a quantitative study of the dependence of polar cusp latitude on the interplanetary magnetic fie1d, Radio Science, $\underline{8}, 9.55,1973 \mathrm{~b}$.

Burton, R. K., R. L. McPherron, and C. T. Russe11, An empirical relationship between Dst and the solar wind electric field and dynamic pressure, in the Proceedings of the Chapman Memorial Symposium on Magnetospheric Motions, Boulder, Colo., June 1973.

Caan, M. N., R. L. McPherron, C. T. Russe11, and N. E. Cline, Statistica1 analysis of tail lobe magnetic variations and their causes, in Proceedings of the Chapman Memorial Symposium on Magnetospheric Motions, P. 103, Boulder, Colo., June 1973a.

Caan, M. N., R. L. McPherron, and C. T. Russe11, Solar wind and substormrelated changes in the lobes of the geomagnetic tail, J. Geophys. Res. 78, $8087,1973 \mathrm{~b}$.

Camidge, F. P., and G. Rostoker, Magnetic field perturbations in the magnetotail associated with polar magnetic substorm, Can. J. Phys., $\underline{48}$, 2002,1970 .

Carpenter, D. L., and C. G. Park, on what ionospheric workers should know about the plasmapause-plasmasphere, Rev. Geophys. Space Phys., 11, 133, 1973.

Cassen, P. and J. Szabo, The viscous magnetopause, planet. Space Sci., 18, 349,1970 .

Chappe11, C. R., The convergence of fact and theory on magnetospheric convection, to be published in the Proceedings of the Seventh Eslab Symposium on Correlated Interplanetary and Magnetospheric Observations, Saulgau, West Germany, May, 1973. 
Coleman, P. J., Jr., and R. L. Rosenberg, North-south component of the interplanetary magnetic field, J. Geophys. Res., 76, 2917, 1971.

Coroniti, F. V., and C. F. Kennel, Can the ionosphere regulate magnetospheric convection?, J. Geophys. Res., 78, 2837, 1973.

Cowley, S. W. H., A qualitative study of the reconnection between the earth's magnetic field and an interplanetary field of arbitrary orientation, Radio Science, $\underline{8}, 903,1973$.

Cowling, T. G., Magnetohydrodynamics, Interscience Publishers, New York, 1956.

Davis, T. N., and R. Parthasarathy, The relationship between polar magnetic activity DP and growth of the geomagnetic ring current, $\mathrm{J}$. Geophys. Res., 72, 5825, 1967.

Dessler, A. J., Vacuum merging: a possible source of the magnetospheric cross-tail electric field, J. Geophys. Res., 76, 3174, 1971.

Dessler, A. J., and J. A. Fejer, Interpretation of $\mathrm{Kp}$ index and M-region geomagnetic storms, Planet. Space Sci., 11, 505, 1963.

Dungey, J. W., Interplanetary magnetic field and the auroral zones, Phys. $\underline{\text { Rev. Letters, }} \underline{6}, 47,1961$.

Dungey, J. W., The structure of the ionosphere, or adventures in velocity space, in Geophysics: The Earth's Environment, ed. by DeWitt, Hiebolt and Lebeau, pp. 526-537, Gordon and Breach, New York, 1963.

Fairfield, D. H., The ordered magnetic field of the magnetosheath, J. Geophys. Res., 72, 5865, 1967.

Fairfield, D. H., Average and unusual $1 \propto$ ations of the earth's magnetopause and bow shock, J. Geophys. Res., 28, 6971, 1971. 
Fairfield, D. H., and L. J. Cahil1, Jr., Transition region magnetic field and polar magnetic disturbances, J. Geophys. Res., 71, 155, 1966.

Fairfie1d, D. H., and N. F. Ness, Configuration of the geomagnetic tail during substorms, J. Geophys. Res., 75, 7032, 1970.

Foster, J. C., D. H. Fairfield, K. W. Ogilvie, and T. J. Rosenberg, Relationship of interplanetary parameters and occurrence of magnetospheric substorms, J. Geophys. Res., 76, 6971, 1971.

Frank, L. A., Charged particle entry, into the earth's magnetosphere, in Proceedings of the Chapman Memorial Symposium on Magnetospheric Motions, 1973.

Frank, L. A., and K. L. Ackerson, Local time survey of plasma at low altitudes over the auroral zones, J. Geophys. Res., 77, 4116, 1972.

Friis-Christensen, E., K. Lassen, J. Wilhjelm, J. M. Wilcox, W. Gonzalez, and D. S. Colburn, Critical component of the interplanetary magnetic field responsible for large geomagnetic effects in the polar cap, J. Geophys. Res., 77, 3371, 1972 .

Garrett, H. B., The role of fluctuations in the interplanetary magnetic field in determining the magnitude of substorm activity, submitted to Planet. Space Sci., 1973.

Gold, T., Motions in the magnetosphere of the earth, J. Geophys. Res., 64, 1219,1959 .

Gonzalez, W. D., A quantitative three dimensional model for magnetopause reconnection, Ph.D. Thesis, Univ. of Calif. Berkeley, 1973.

Gurnett, D.A., and L. A. Frank, Observed relationships between electric fields and auroral particle precipitation, J.Geophys. Res., 78, 145, 1973. 
Heppner, J. P., Polar cap electric field distributions related to the interplanetary magnetic field direction, J. Geophys. Res., 77, 4877, 1972 . Heppner, J. P., High latitude electric fields and the modulations related to interplanetary magnetic field parameters, Radio Science, 8, 933, 1973. Hi11, T. W., A three-dimensional model of magnetic merging at the magnetopause, Radio Science, $8,915,1973$.

Hirshberg, J., and D. S. Colburn, Interplanetary field and geomagnetic variations -- a unified view, Planet. Space Sci., 1183, 1969. Hoffman, R. A., and J. L. Burch, Electron precipitation patterns and substorm morphology, J. Geophys. Res., 78, 2867, 1973. Holzer, T. E., and G. C. Reid, Electrodynamic coupling in the dayside magnetosheath-magnetosphere-ionosphere system, EOS Trans. AGU, 54, 414, 1973. Hones, E. W., Ir., Plasma flow in the plasma sheet and its relation to substorms, Radio Science, $\underline{8}, 979,1973$.

Hones, E. W., Jr., J. R. Asbridge, S. J. Bame, M. D. Montgomery, S. Singer and S.-I. Akasofu, Measurements of magnetotail plasma flow made with Ve1a 4B, J. Geophys. Res., 77, 5503, 1972 .

Hones, E. W., Jr., J. R. Asbridge, S. J. Bame, and S. Singer, Substorm variations of the magnetotail plasma sheet from Xsm $\approx-6 R_{E}$ to Xsm $\approx-60$ RE$_{\mathrm{E}}$, J. Geophys. Res., 78, 109, 1973. Hones, E. W., Jr., S. Singer, L. J. Lanzerotti, J. D. Pierson, and T. J. Rosenberg, Magnetospheric substorm of August 25-26, 1967, I. Geophys. Res., 76, 2977, 1971 .

Iijima, T., Relationship of magnetospheric substorms on the ground and in the distant magnetotail, Rep. of Ionosphere and Space Res. in Japan, 26, 149, 1972. 
Kane, R. P., Relationship between interplanetary plasma parameters and Dst, to be published in J. Geophys. Res., 1973.

Kawasaki, K., and S.-I. Akasofu, A possible current system associated with the $\mathrm{S}_{\mathrm{q}}^{\mathrm{P}}$ variation, $\underline{\text { Planet. Space Sci. }}, \underline{21}, .329,1973$.

Kawasaki, K., and C.-I. Meng, Low-1atitude positive bay and polar magnetic substorm onsets, EOS, Trans. AGU, 54, 1174, 1973.

Kawasaki, K., S.-I. Akasofu, F. Yasuhara, and C.-I. Meng, Storm sudden commencements and polar magnetic substorms, J. Geophys. Res., 76, 6781, 1971.

Kawasaki, K., F. Yasuhara, and S.-I. Akasofu, Short-period interplanetary and polar magnetic field variations, Planet. Space Sci., 21, 1973.

Kive1son, M. G., C. T. Russe11, M. Neugebauer, F. I. Scarf, and R. W. Fredricks, Dependence of the polar cusp on the north-south component of the interplanetary magnetic fie1d, J. Geophys. Res., $\underline{78}, 3761,1973$. Kokubun, S., Relationship of interplanetary magnetic field structure with development of substorm and storm main phase, P1anet. Space Sci., 20, 1033,1972 .

Levy, R. H., H. E. Petschek, and G. L. Siscoe, Aerodynamic Aspects of the magnetospheric flow, AIAA Journa1, 2, 2065, 1964.

Lin, R. P., and K. A. Anderson, Evidence for connection of geomagnetic tail lines to the interplanetary field, J. Geophys. Res., 71, 4213, 1966.

Mansurov, S. M., New evidence of a relationship between magnetic fields in space and on earth, Geomagn. Aeron., $\underline{9}, 622,1969$.

McIlwain, C.E., Substorm injection boundaries, Presented at The Summer Advanced Study Institute on Earth's Particles and Fields, Sheffield, England, 1973. 
McPherron, R. L., Growth phase of magnetospheric substorms, J. Geophys. $\underline{\text { Res. }}, \underline{75}, 5592,1970$.

McPherron, R. L., The substorm expansion: An ionospheric short circuit of the tail current?, Presented at IAGA Second General Assembly, Kyoto, Japan, Sept. 1973.

Meng, C.-I., Variation of the magnetopause position with substorm activity, J. Geophys. Res., 25, 3252, 1970 .

Meng, C.-I., and S.-I. Akasofu, A study of polar magnetic substorms, 2, Three dimensiona1 current system, J. Geophys. Res., 74, 4035, 1969. Meng, C.-I., and D. S. Colburn, Magnetotail variations associated with the southward interplanetary magnetic field, Univ. of Calif, at Berkeley Space Sciences Laboratory Preprint Series 14 Issue 29, May 1973.

Meng, C.-I., B. Tsurutani, K. Kawasaki and S.-I. Akasofu, Cross-correlation analysis of the $\mathrm{AE}$ index and the interplanetary magnetic field $\mathrm{B}_{\mathrm{z}}$ component, J. Geophys. Res., 78, 617, 1973.

Mihalov, J. D., D. S. Colburn, R. G. Currie, and C. P. Sonett, Configuration and reconnection of the geomagnetic tail, J. Geophys. Res., 73, 943, 1968.

Morfill, G., and M. Scholer, Reconnection of the geomagnetic tail deduced from solar-particle observations, J. Geophys. Res., 77, 4021, 1972 . Morfil1, G., and M. Scholer, Study of the magnetosphere using energetic solar particles, submitted to Space Science Reviews, 1973. Mozer, F. S., and W. D. Gonzalez, Response of polar cap convection to the interplanetary magnetic field, J. Geophys. Res., 78, 6784, 1973. 
Mozer, F. S., W. D. Gonzalez, F.. Bogott, M. C. Kelley and S. Schutz, High latitude electric fields and the three-dimensional interaction between the interplanetary and terrestrial magnetic fields, submitted to J. Geophys. Res., 1973.

Ness, N. F., The earth's magnetic tail, J. Geophys. Res., 70, 2989, 1965.

Nishida, A., and E. W. Hones, Jr., The association of plasma-sheet thinning with neutral-line formation in the magnetotail, submitted to J. Geophys. Res., 1973.

Nishida, A., and $S$. Kokubun, New polar magnetic disturbances: $\mathrm{s}_{\mathrm{q}}^{\mathrm{p}}$, $\mathrm{SP}$, DPC, and DP2, Rev. Geophys. Space Phys., 9, 417, 1971.

Nishida, A., and K. Maezawa, Two basic modes of interaction between the solar wind and the magnetosphere, J.Geophys. Res., 76, 2254, 1971. Nishida, A., and N. Nagayama, Synoptic survey for the neutral line in the magnetotail during the substorm expansion phase, J. Geophys. Res., $3782,1973$.

Parks, G. K., and R. Pellat, Correlation of interplanetary-space Bz field fluctuations and trapped-particle redistribution, J. Geophys, Res., 77, 266,1972 .

Parks, G. K., G. Laval and R. Pellat, Behavior of outer radiation zone and a new mode1 of magnetospheric substorm, planet. Space Sci., 20, 1391,1972

Petschek, H. E., Magnetic field annihilation, in AAS-NASA Symposium on the Physics of Solar Flares, ed. by W. N. Hess, NASA SP-50, 1964.

Petschek, H. E., The mechanism for reconnection of geomagnetic and interplanetary field lines, in The Solar Wind, ed. by R. J. Mackin, Jr., and M. Neugebauer, Pergamon Press, New York, p. 257, 1966. 
Pike, C. P., C.-I. Meng, S.-I. Akasofu, and J. A. Whalen, Observed correlations between interplanetary magnetic field variations and the dynamics of the auroral oval and the high-latitude ionosphere, Submitted to J. Geophys. Res., 1973.

Reid, G. C., and T. E. Holzer, The transient response of magnetospheric convection to changes in the rate of field-line reconnection, EOS Trans. AGU, $54,414,1973$.

Rosenbauer, H., H. Grïnwaldt, G. Paschmann, and N. Sckopke, P1asmaobservations from HEOS-2, IAGA, 2nd General Scientific Assembly, Kyoto, Japan, 1973.

Rostoker, G., Polar magnetic substorms, Rev. Geophys. Space Phys., 10, 157,1972 .

Rostoker, G., Geomagnetic indices, Rev. Geophys. Space Phys., 10, 935, 1972.

Rostoker, G., and F. P. Camidge, Localized character of magnetotail magnetic fluctuations during polar magnetic substorms, J. Geophys. Res., 76, 6944,1971 .

Rostoker, G., H.-L. Lam, and W. D. Hume, Response time of the magnetosphere to the interplanetary electric field, Can. J. Phys., 50, 544, 1972.

Russell, C. T., Geophysical coordinate transformations, Cosmic Electrodynamics, 2, 184, 1971 .

Russe11, C. T., The solar wind and magnetospheric dynamics, in the Proceedings of the Seventh Eslab Symposium on correlated interplanetary and magnetospheric observations, Saulgau, F.R.G., May 1973. 
Russe11; C.T., and R. L. McPherron, Semiannual variation of geomagnetic activity, J. Geophys. Res., 78, 92, 1973a.

Russe11, C. T., and R. L. McPherron, The magnetotail and substorms, to be published in Space Science Reviews, $1973 \mathrm{~b}$.

Russe11, C. T., C. R. Chappe11, M. D. Montgomery, M. Neugebauer, and

F. L. Scarf, OGO-5 observations of the polar cusp on November 1, 1968, J. Geophys. Res., 76, 6743, 1971 .

Russe11, C. T., R. L. McPherron and R. K. Burton, On the cause of geomagnetic storms, submitted to J.Geophys. Res., 1973.

Russe11, C. T., M. Neugebauer, and M. G. Kivelson, OGO-5 observations of the magnetopause, in the Proceedings of the Seventh Eslab Symposium on correlated interplanetary and magnetospheric observations, Saulgau, F. R. G., May 1973 .

Saito, T., Recurrent magnetic storms in relation to the structure of solar and interplanetary magnetic fields, Rep. of Ionosphere and Space Res. in Japan, 26, 245, 1972.

Schindler, K., and N. F. Ness, Internal structure of the geomagnetic neutra1 sheet, J. Geophys. Res., 77, 91, 1972 .

Siscoe, G. L., and W. D. Cummings, on the cause of geomagnetic bays, Planet. Space. Sci. , 17, 1795, 1969.

Snyder; A. L., S.-I. Akasofu, and C. P. Pike, The day-sector polar F-1ayer during a monetospheric substorm, Planet. Space Sci., 21, 399, 1973.

Sonett, C. P., D. S. Colburn, R. G. Currie, and J. D. Mihalov, The geomagnetic tail: Topology, reconnection, and interaction with the moon, in Physics of the Magnetosphere, 1968.

Sonnerup, B. U. Ö., Magnetic-field re-connexion in a highly conducting incompressible fluid, J. Plasma Phys., 4, 161, 1970. 
Sonnerup, B. U. O., Magnetopause structure during the magnetic storm of September 24, 1961, J. Geophys. Res., 76, 6717, 1971.

Sonnerup, B. U. 8., Magnetic fieid reconnection and particle acceleration, in High Energy Phenomena on the Sun Symposium Proceedings, ed, by R. Ramaty and R. G. Stone, NASA X-693-73-193, p. 357, 1973a.

Sonnerup, B. U. O., The reconnecting magnetosphere, in the Proceedings of the Summer Advanced Study Institute on Earth's Particles and Fields, Sheffield, England, August 1973b.

Stern, D. P., A study of the electric field in an open magnetospheric mode1, J. Geophys. Res., 78, 1973.

Svalgard, I., Sector stmucture of the interplanetary magnetic field and daily variation of the geomagnetic field at high latitudes, Geophys. Pap. R-6, 11 pp., Dan. Metero1. Inst., Copenhagen, 1968. Svaalgard, L., Polar cap magnetic variations and their relationship with the interplanetary magnetic sector structure, J. Geophys. Res., 78, 1973.

Tsurutani, B. T., and C.-T. Meng, Interplanetary magnetic-field variations and substorm activity, J. Geophys. Res., 77, 2964, 1972.

Unti, T., and G. Atkinson, Two-dimensional Chapman-Ferraro problem with neutra1 sheet, 1, the boundary, J. Geophys. Res., 73, 7319, 1968. Vasyliunas, V. M., The inter-relationship of magnetospheric processes, in Earth's Magnetospheric Processes, ed. by B. M. McCormac, D. Reidel, Dordrecht, Holland, 1972.

Walbridge, E., The limiting of magnetospheric convection by dissipation in the ionosphere, J. Geophys. Res., 72, 5213, 1967. 
Wehrenberg, P., and G. K. Parks, The interaction of the solar wind electric field and the magnetosphere, in the Proceedings of the Chapman Memorial Symposium on Magnetospheric Motions, Boulder, Colo., June 1973.

Weins, R. G., and G. Rostoker, Ground-based magnetic signatures of the phases of magnetospheric substorms -- a reconciliation, EOS Trans. AGU, $\underline{54}, 412,1973$.

Wilcox, J. M., Inferring the interplanetary magnetic field by observing the polar geomagnetic field, Rey. Geophys. and Space Phys., 10, 1003, 1972 .

Wilcox, J. M., K. H. Schatten, and N. F. Ness, Influence of interplanetary magnetic field and plasma on geomagnetic activity during quiet-sun conditions, J. Geophys. Res., 72, 19, 1967.

Wolf, R. A., Calculations of magnetospheric electric fields, to be published in the Proceedings of the Summer Advanced Study Institute, Sheffield, England, Aug. 1973.

Yasuhara, F., S.-I. Akasofu, J. D. Winningham, and W. J. Heikkila, The equatorward shift of the cleft during magnetospheric substorms as observed by ISIS-1, J. Geophys. Res., 78, Nov. 1973. 


\section{FIGURE CAPTIONS}

Figure 1. Average percentage of the maximum value of the $\mathrm{AE}$ index and solar-magnetospheric north-south component of the IMF during 54 isolated substorms. Taken from Foster et a1 (1971).

Figure 2. Average behavior of the IMF solar-magnetospheric north-south component, the midlatitude $\mathrm{H}$ component, the $\mathrm{AE}$ index and the tail-lobe magnetic energy density for 24 isolated substorms. Taken from McPherron (1973).

Figure 3. Sketch of magnetospheric topology in the noon-midnight meridian for conditions which exist at substorm onset. The macroscopic $\mathrm{X}$-type neutral line is generally beyond the orbit of the moon during quiet times. The magnetic loops produced by merging on closed field lines are thought to occur sporadically during quiet and disturbed times.

Figure 4. Interplanetary and magnetotail $\mathrm{B}_{\mathrm{z}}$ in solar-magnetospheric coordinates, plasma-sheet electron pressure, low-latitude magnetograms from Huancayo and Bangui, and magnetograms from severa1 auroral-zone stations on March 24, 1968. The letters $D, F$ and $V$ denote the IMP-D, IMP-F and Vela satellites. The numbers in parentheses following the spacecraft designations are their solar-magnetospheric $X$ and $Y$ components and their approximate distance above or below the neutral sheet. Numbers in parentheses following ground-station names denote the magrietic local time at the universal time marked by the solid vertical 1ine. Taken from Nishida and Hones (1973). 
Figure 5. The solution of Atkinson and Unti (1969) to the two-dimensional Chapman-Ferraro problem with neutral sheet. The parameter $\mathrm{C}^{\prime}$ is proportional to the total tail flux, while the magnetic field strength at the subsolar point is the same for all three cases. Shown are the magnetopause boundary and the last closed midnight field line.

Figure 6. Poleward and equatorward boundaries of polar-cusp electron precipitation versus the previous 45-minute's average IMF $Z$ component in solar-magnetospheric coordinates. Solid curves are second-order fits to the data. Taken from Burch (1973b).

Figure 7. Solid vertical lines denote the regions of polar-cusp electron precipitation for those cases of Figure 6 for which poleward and equatorward boundaries were determined in single polar passes of the sate11ite. Dashed vertical lines are polarcleft proton precipitation regions provided by J. D. Winningham. The second-order fits of Figure 6 are repeated for reference. Figure 8. The interplanetary magnetic record from Explorer 35 in solarequatorial coordinates and the geomagnetic $\mathrm{H}$ record from the Alaska meridian chain of magnetic stations on Jan. 8, 1970 . A contracted-oval substorm began at approximately 1018 UT. Taken from Akasofu et al (1973).

Figure 9. Superimposed traces of the solar-magnetospheric latitude of the interplanetary magnetic field for a period of time before and after the onsets of the four contracted-oval substorms identified by Akasofu et al (1973). The light solid curve, 
Figure 9. heavy solid curve, dashed curve and dotted curve are for the (Cont 'd)

8 Jan. 1970, 15 Jan. 1966, 1 Feb. 1968 and 16 Nov. 1969 substorms respectively.

Figure 10. View from the sun of the result in the dawn-dusk meridian of superimposing a uniform external field and a geomagnetic dipole field. (a) The case for an external field in the $+Y$ direction. The solar-wind electric field is northward. The points $A^{\prime}$ and $B^{\prime}$ denote points in the northern polar cap which connect magnetically to the neutral points $A$ and $B$. The solar-wind electric field maps into a dawn-dusk polar-cap fie1d. (b) The siutation when the external magnetic field is in the $-Y$ direction. The polar-cap electric field is again in the dawn-dusk direction. Taken from Stern (1973).

Figure 11. The normalized potential difference across a merging region of width $D$ as a function of the angle between the magnetic field directions inside (i) and outside (o) the magnetopause or merging region for various ratios of the two field strengths. The parameter $\mathrm{v}_{\mathrm{A}_{0}}$ is the Alfvén velocity outside the magnetosphere, and $k$ is the fraction of the Alfvén velocity with which merging proceeds. Taken from Sonnerup (1973b). 
Figure 12. Plots of the 15-minute averages of the polar-cap dawn to dusk electric fields measured in a nonrotating frame of reference at Thule and Resolute Bay along with 1 -hour averages of the components of the IMF. The bottom curve results from applying the IMF data to a three-dimensional mode1 of reconnection. Taken from Mozer and Gonzalez (1973).

Figure 13. In the upper two pane1s are plotted the square root of the solar-wind dynamic pressure and the square of the east-west component of the solar-wind electric field times its sign. In the lower pane1, the solid curve shows Dst as determined from ground magnetograms, while the predicted Dst, calculated at 2.5-minute intervals is represented by the dashed line. Taken from Burton et al (1973). 


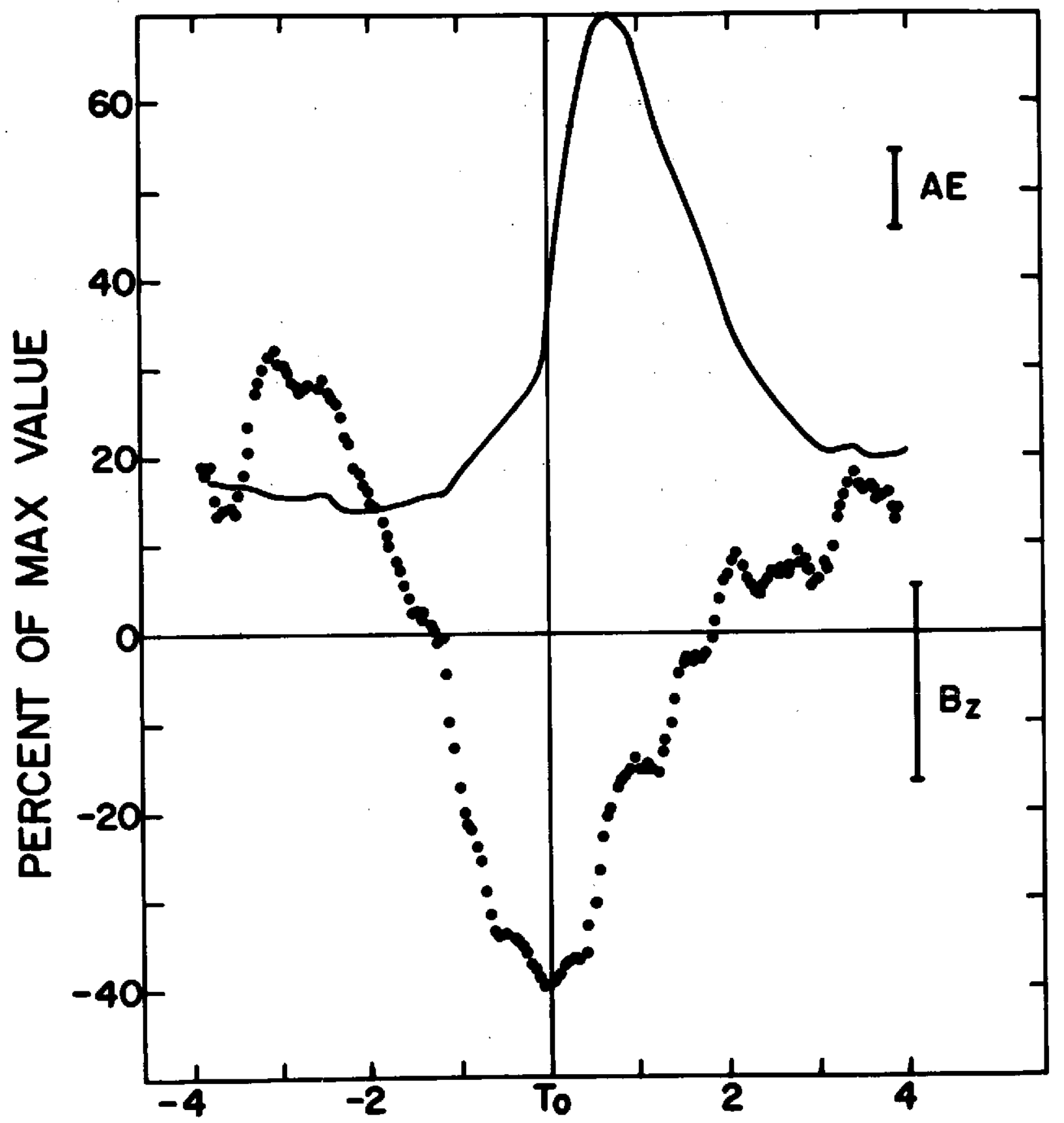

PIgua: 1 
Superposed Epoch Analysis of Magnetospheric Substorms

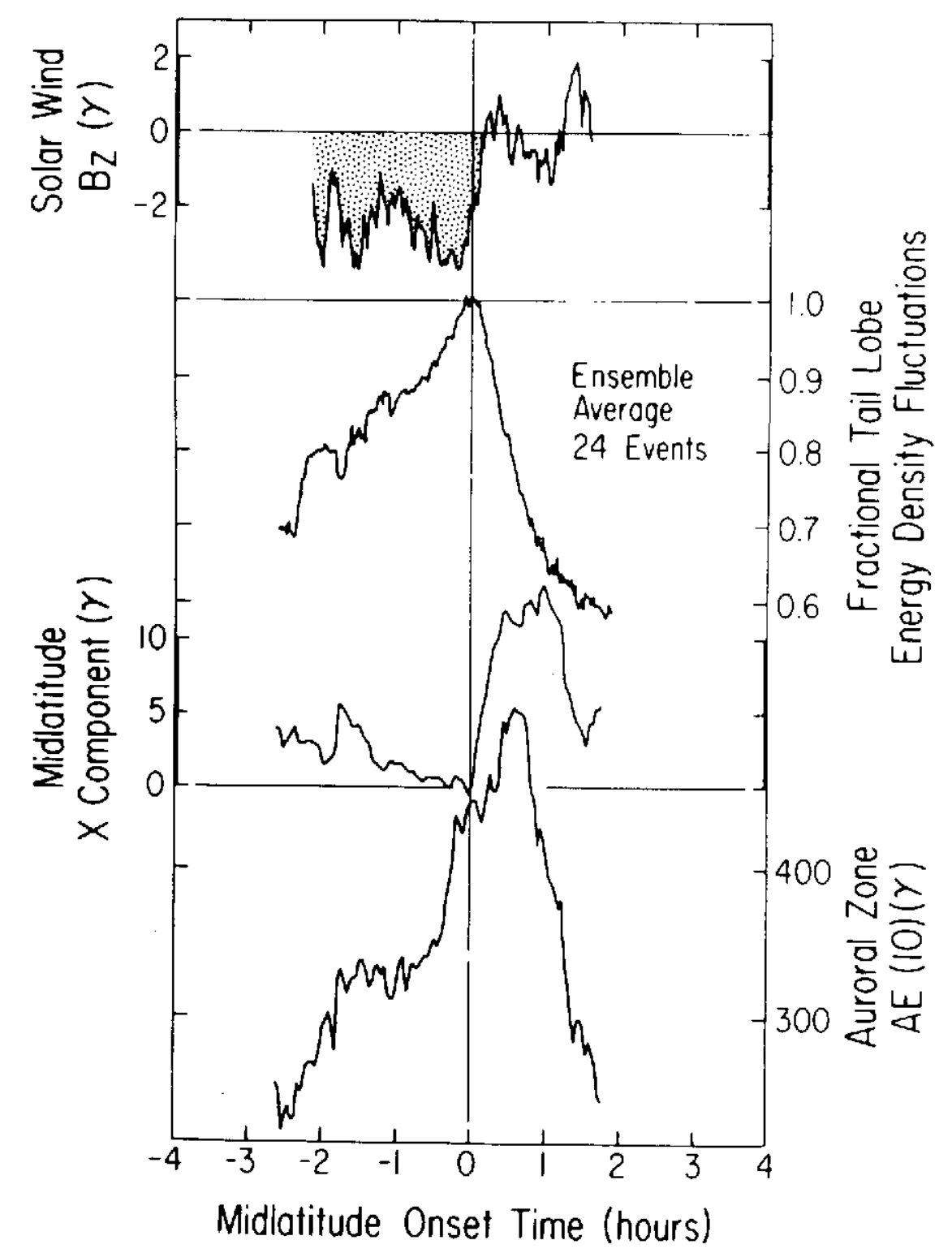

FHARRl: - 


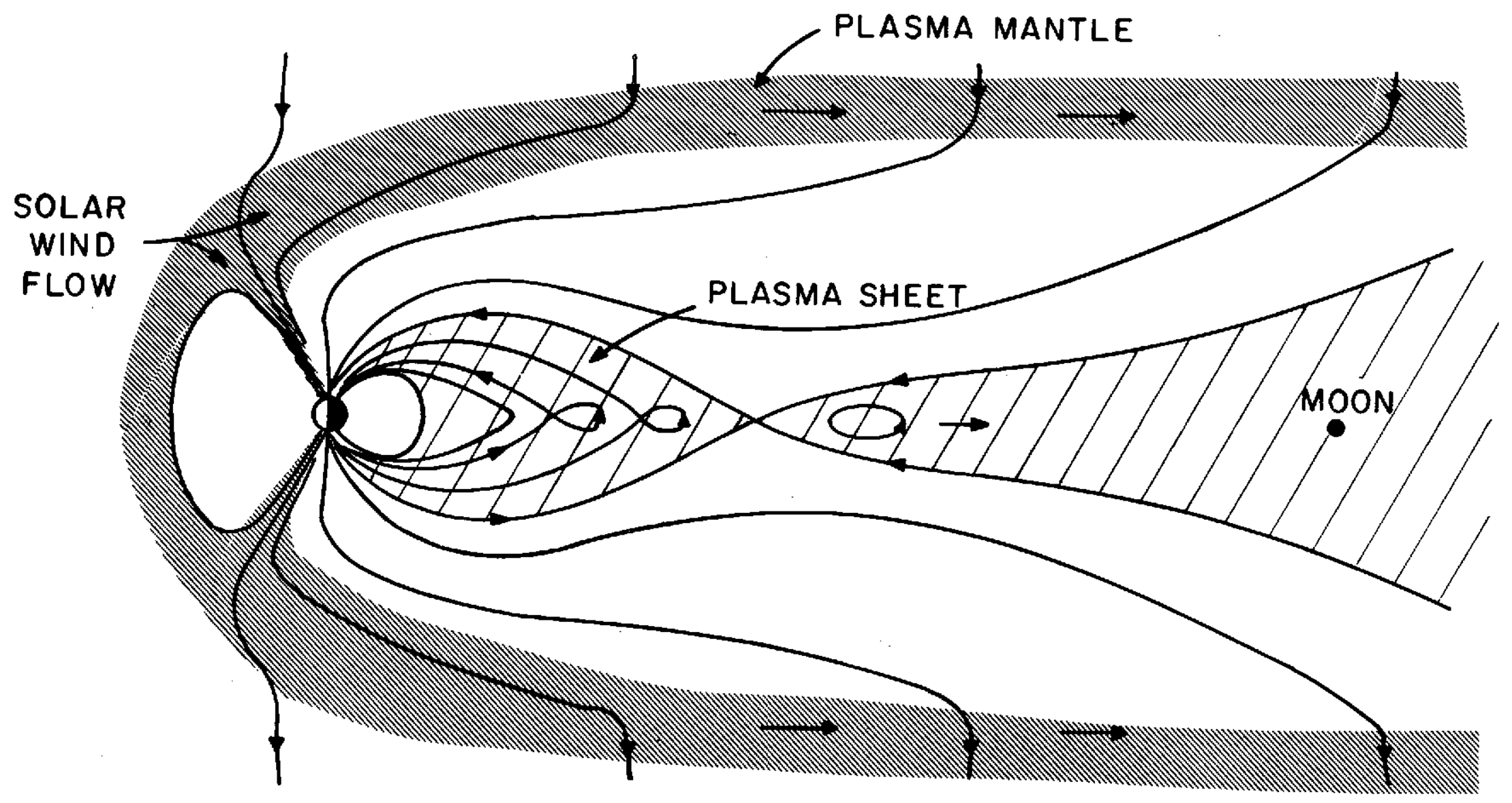



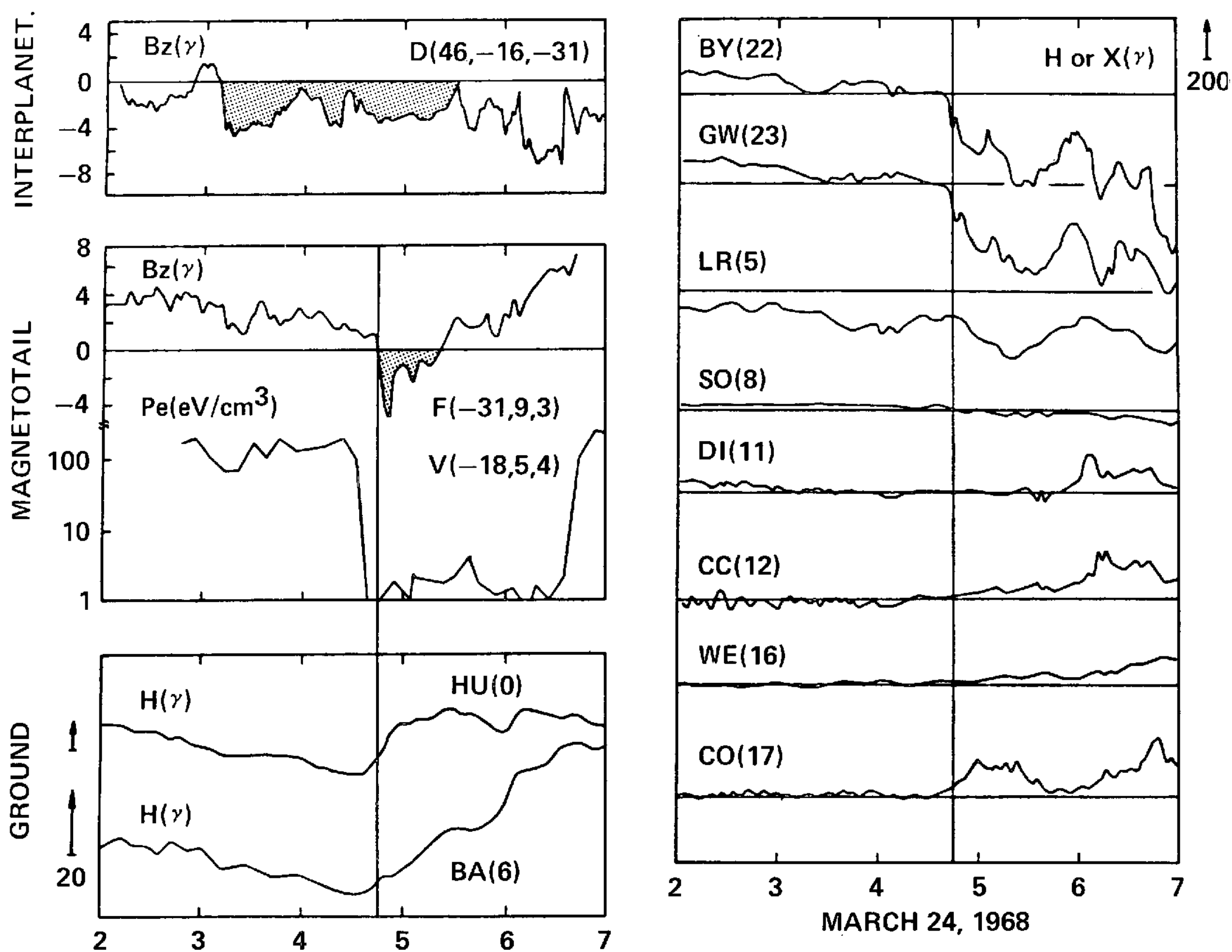

FIGURE 4 


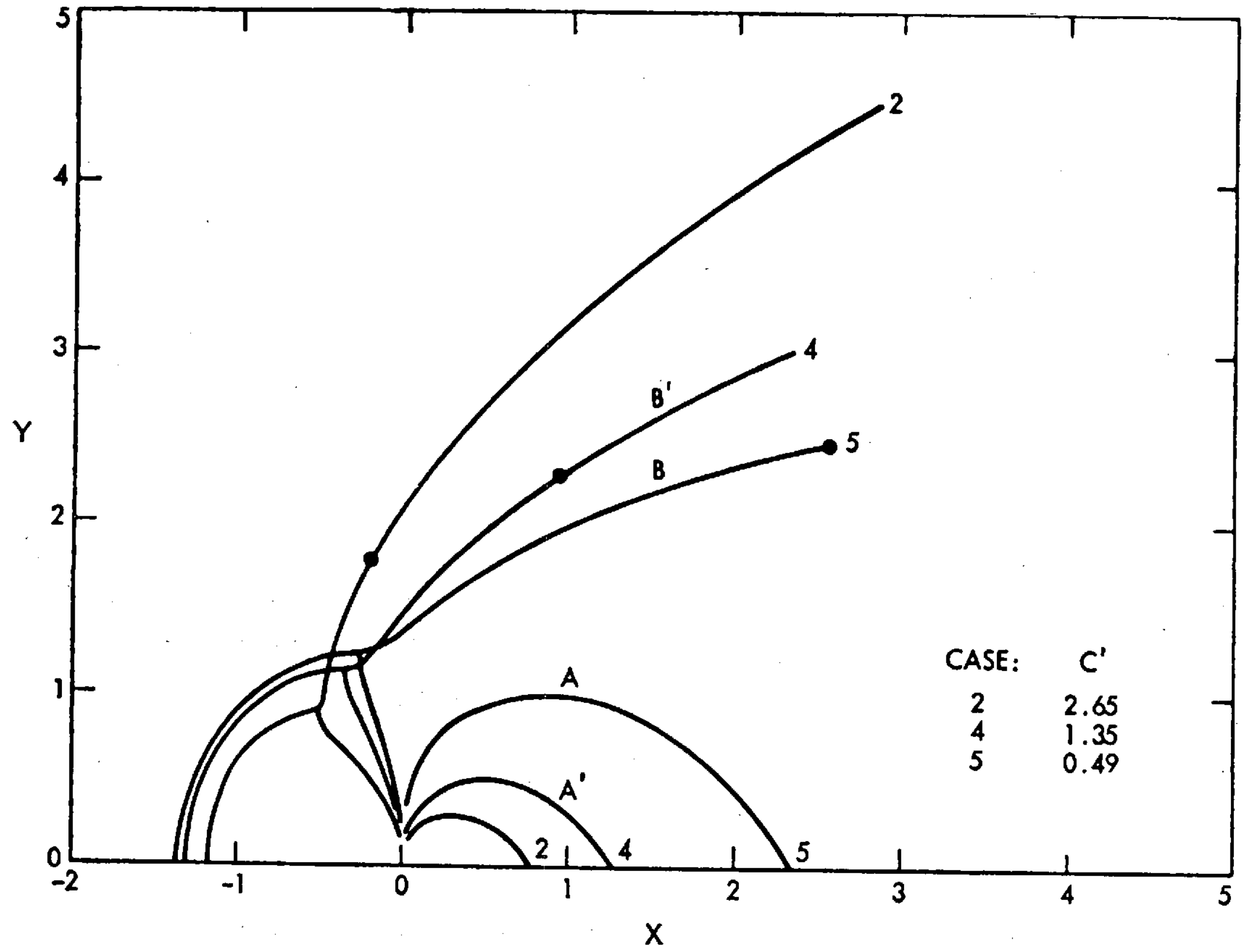

FIGURE 5 


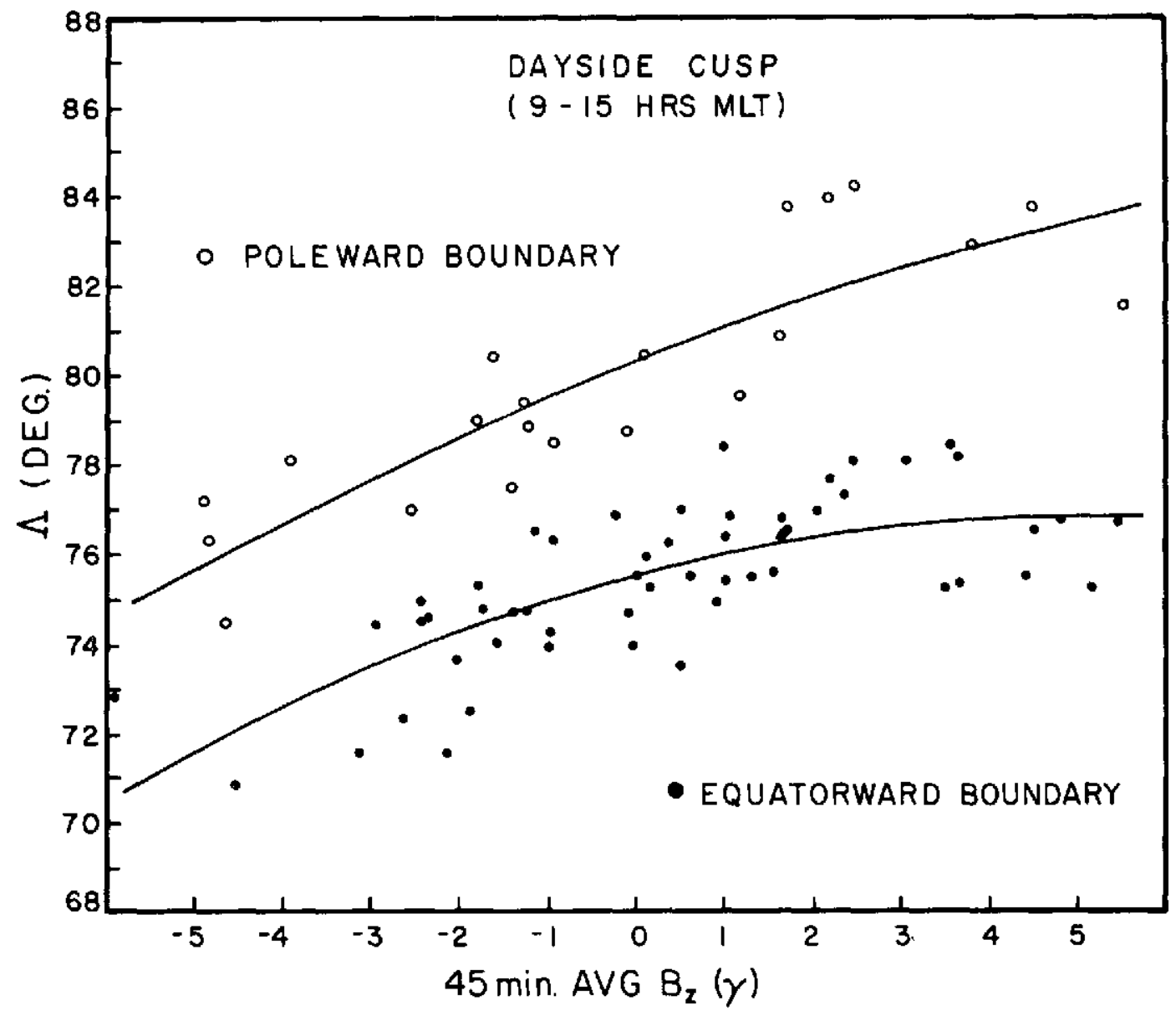

FIGURE 6 


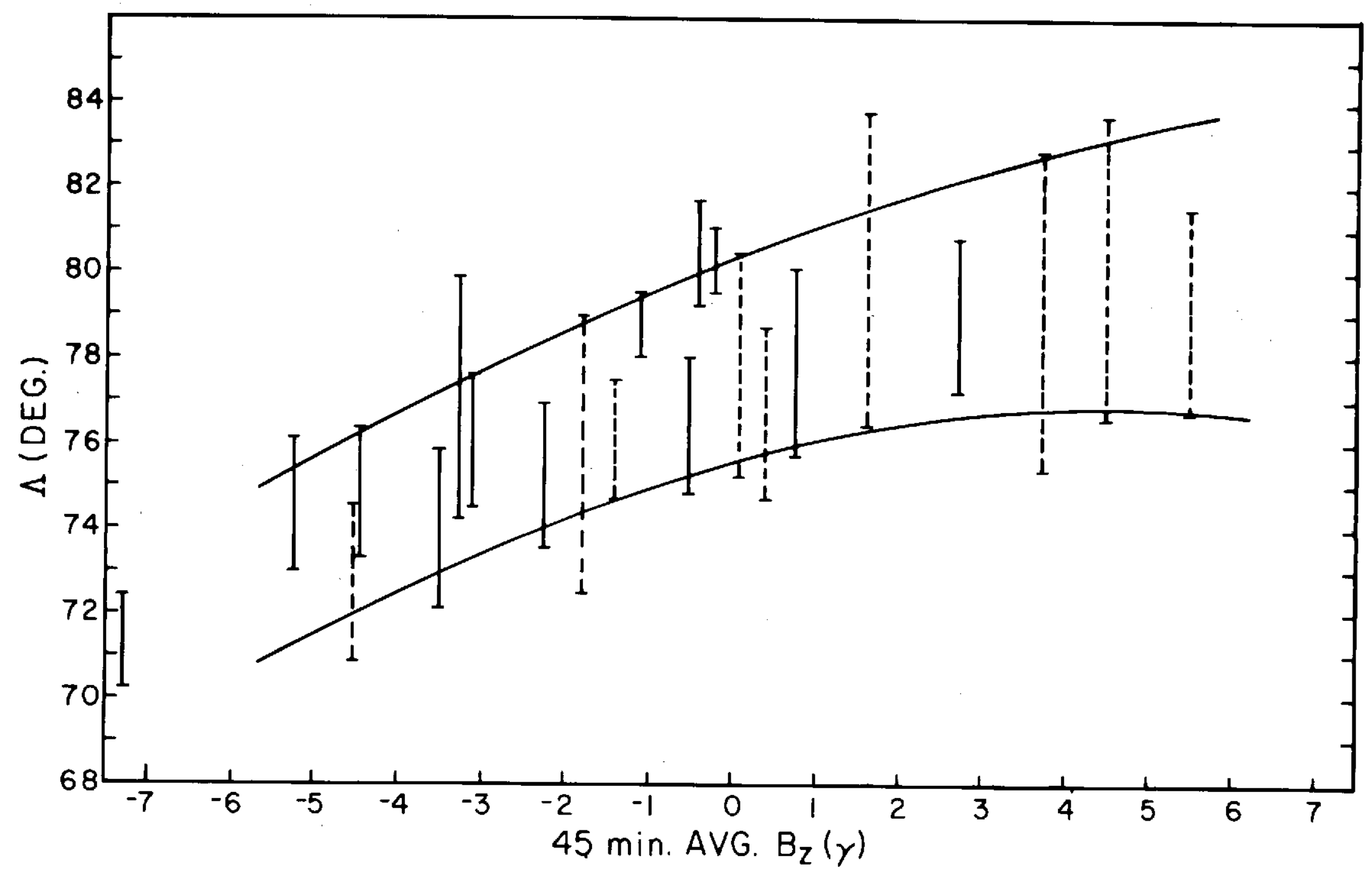

FIGURE 7 

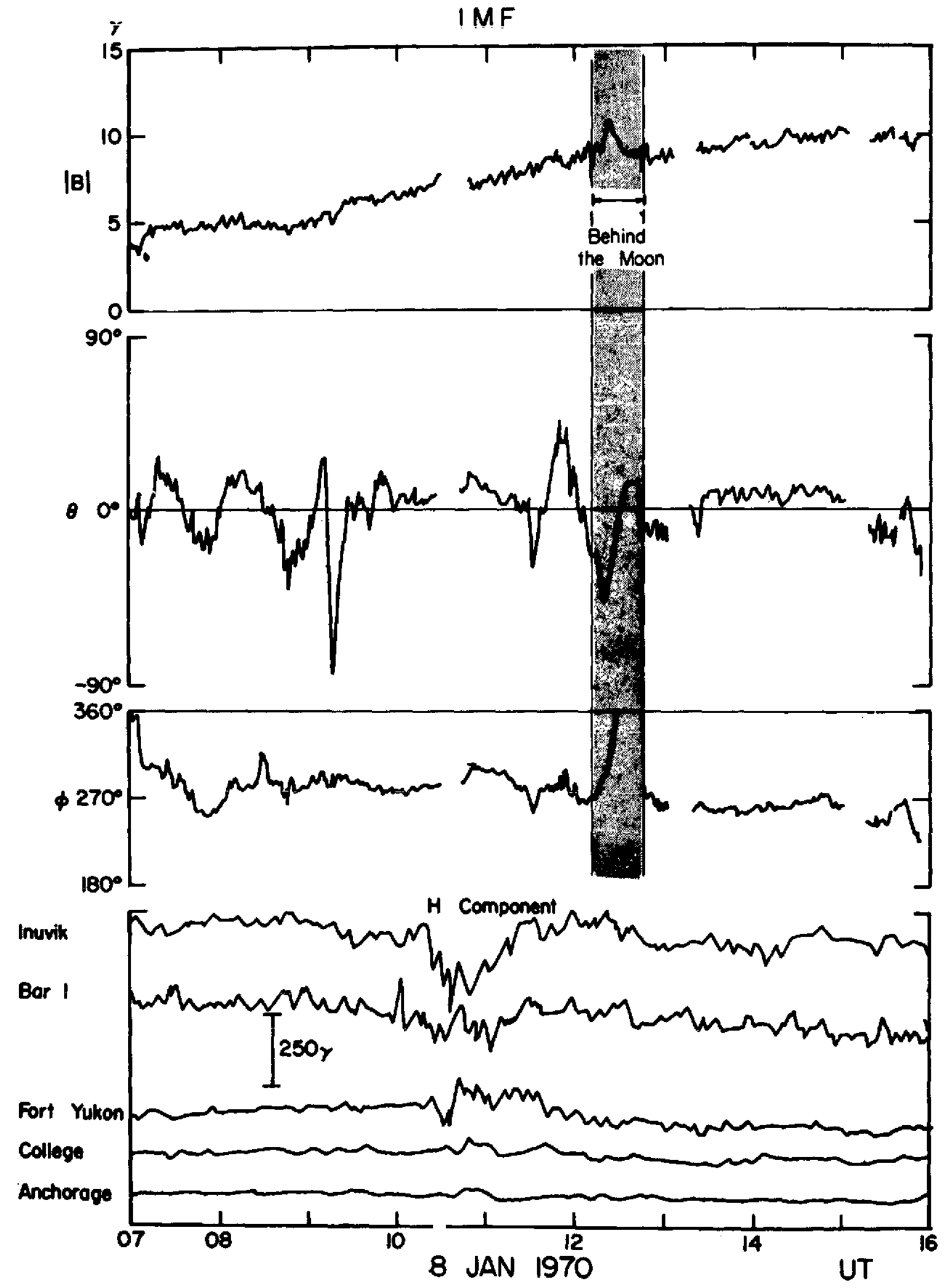

FIGURE 8 


\section{CONTRACTED OVAL SUBSTORMS}

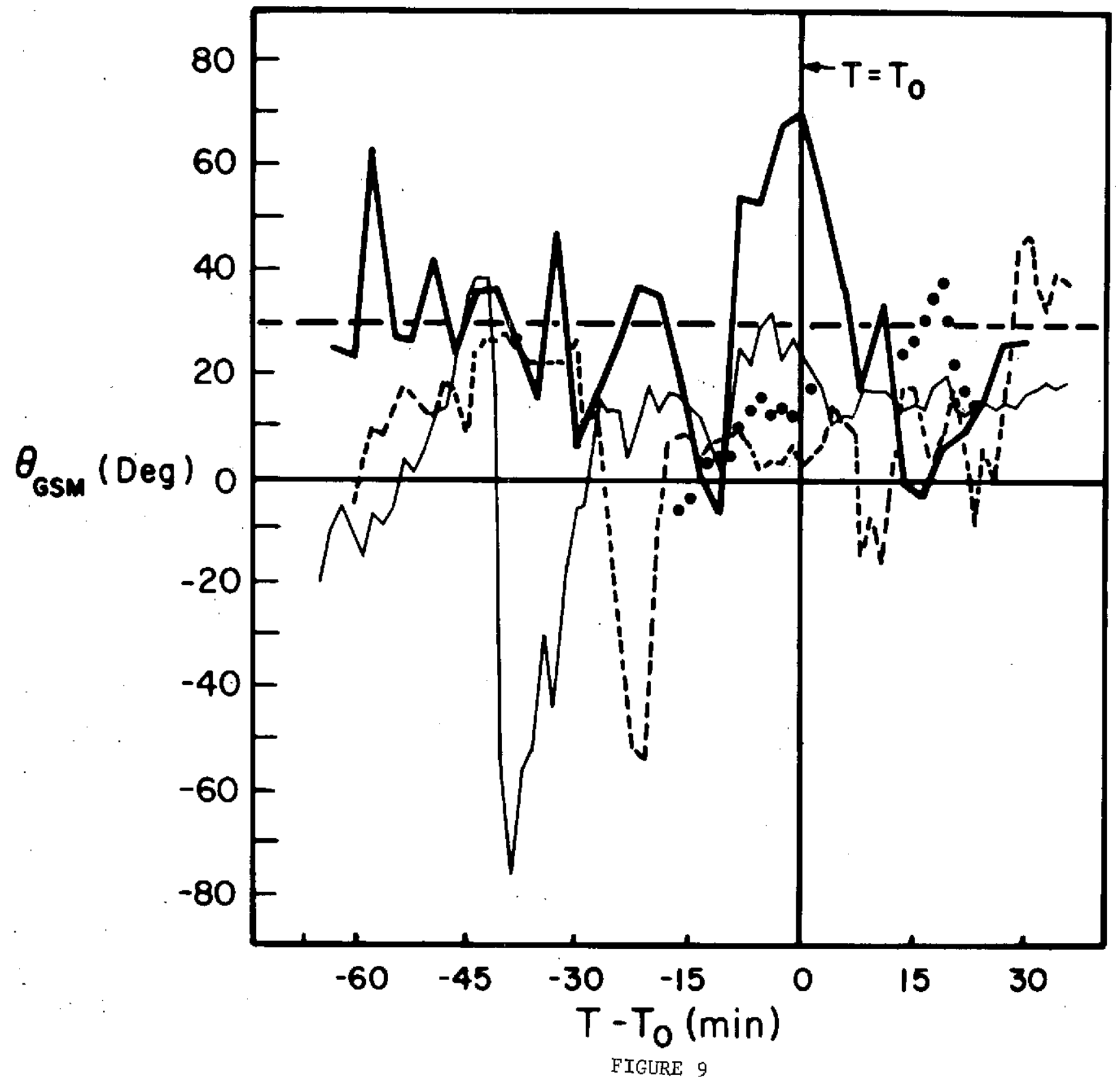




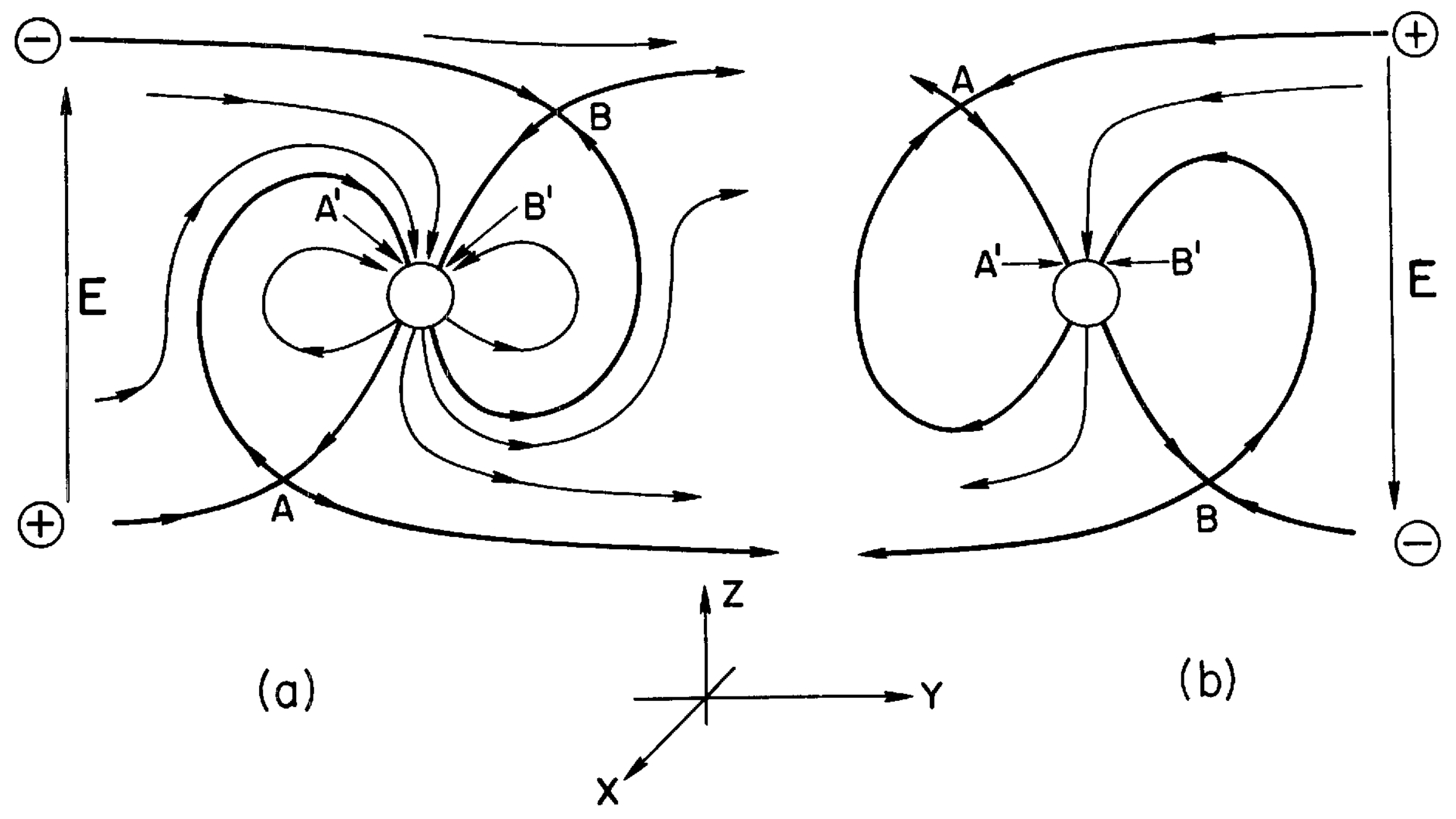

FIGURE 10 
$\frac{\Delta V}{K V_{A_{0}} B_{0} D}$

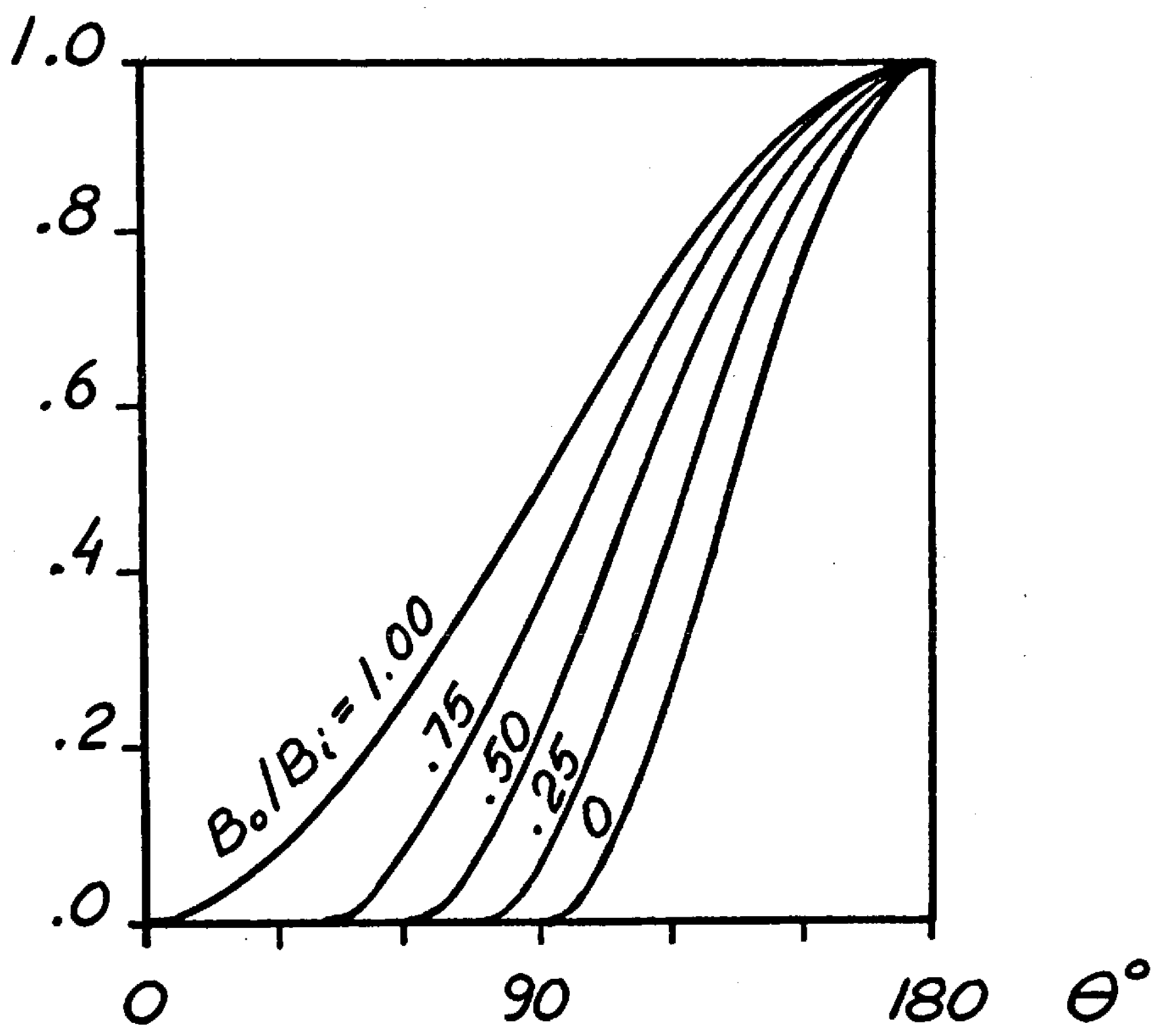

FIGURE 11 

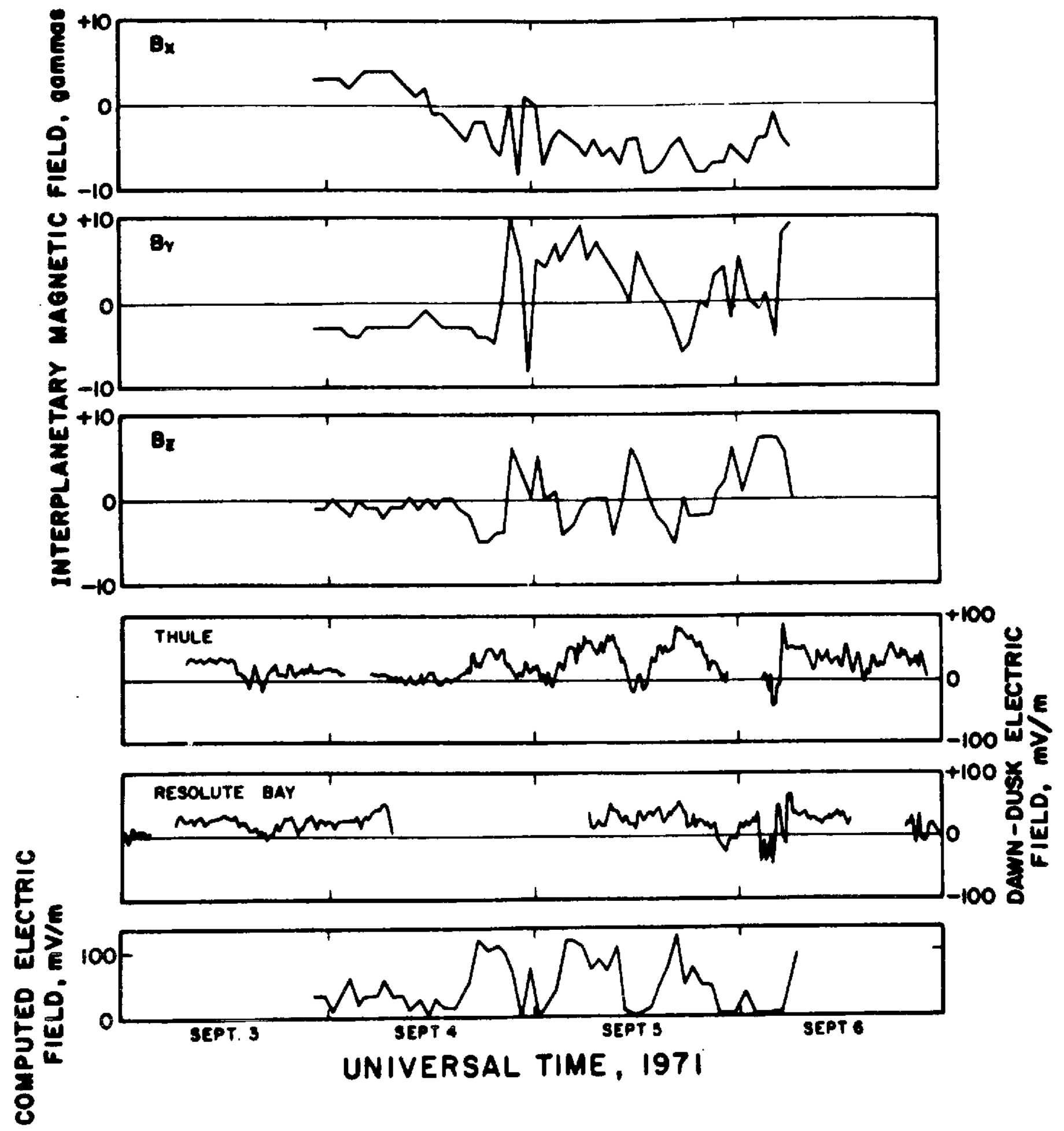

FIGURE 12 
FEBRUARY $23 \quad 24 \quad 1967$
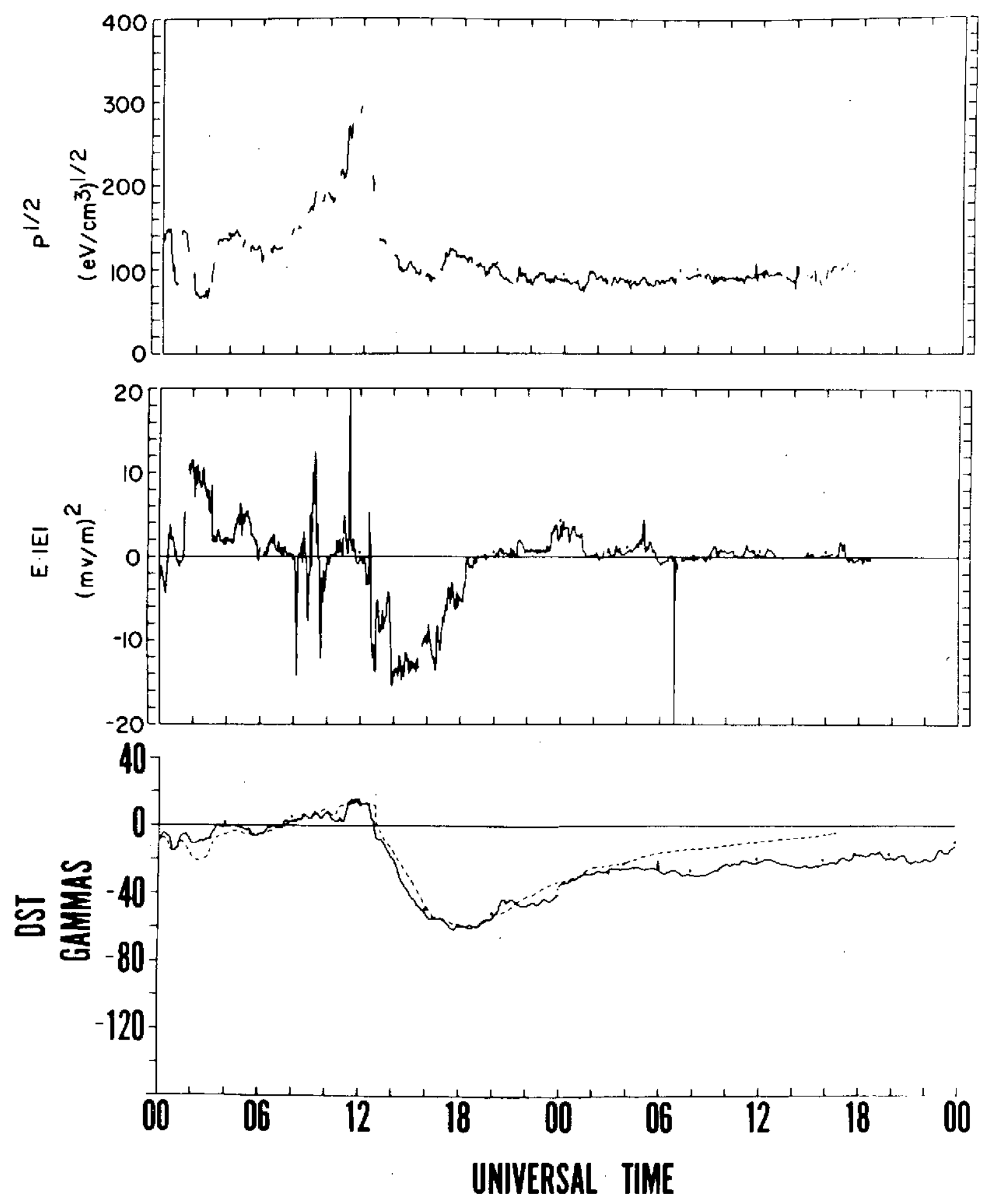

FIGURE 13 